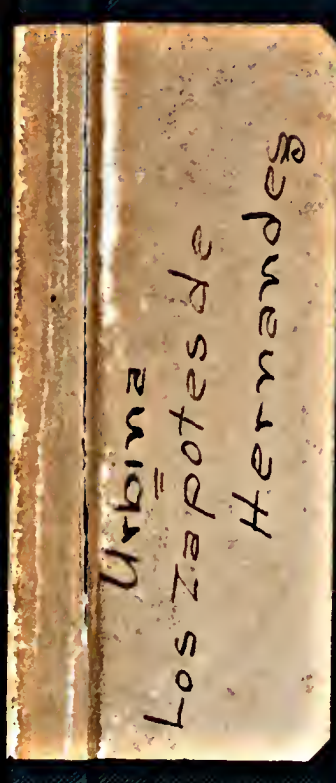

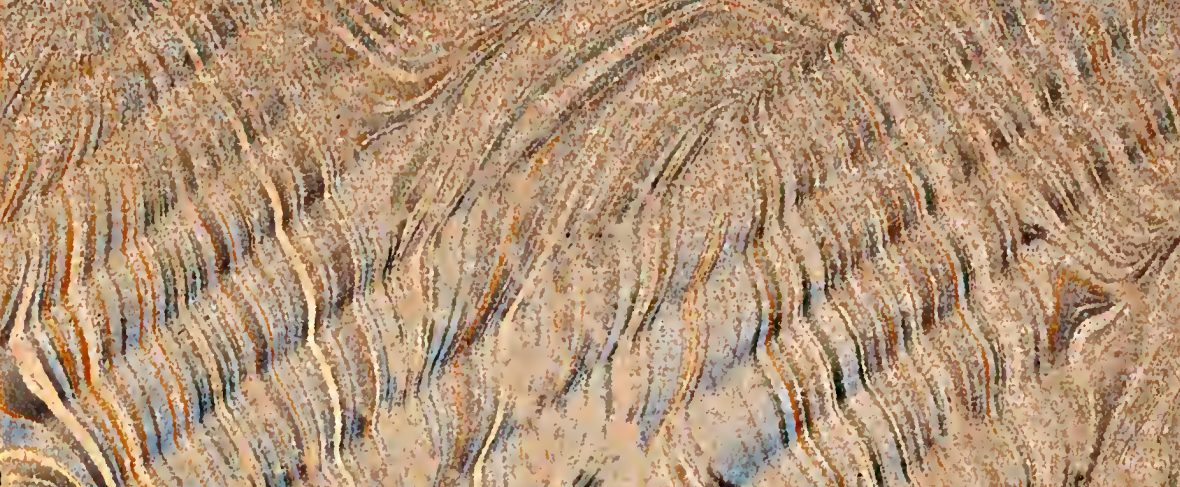

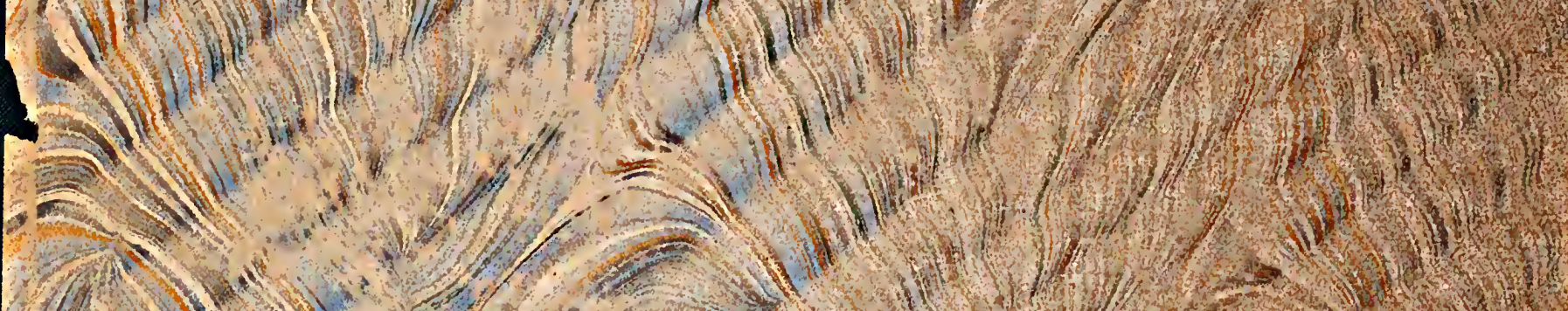

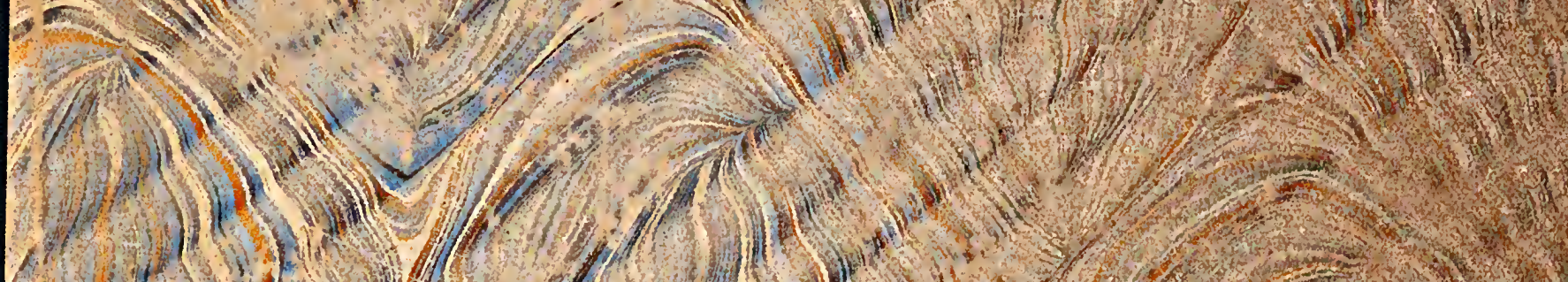

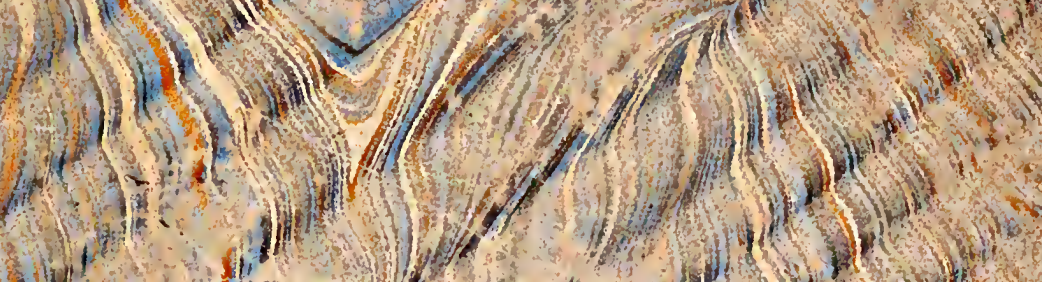

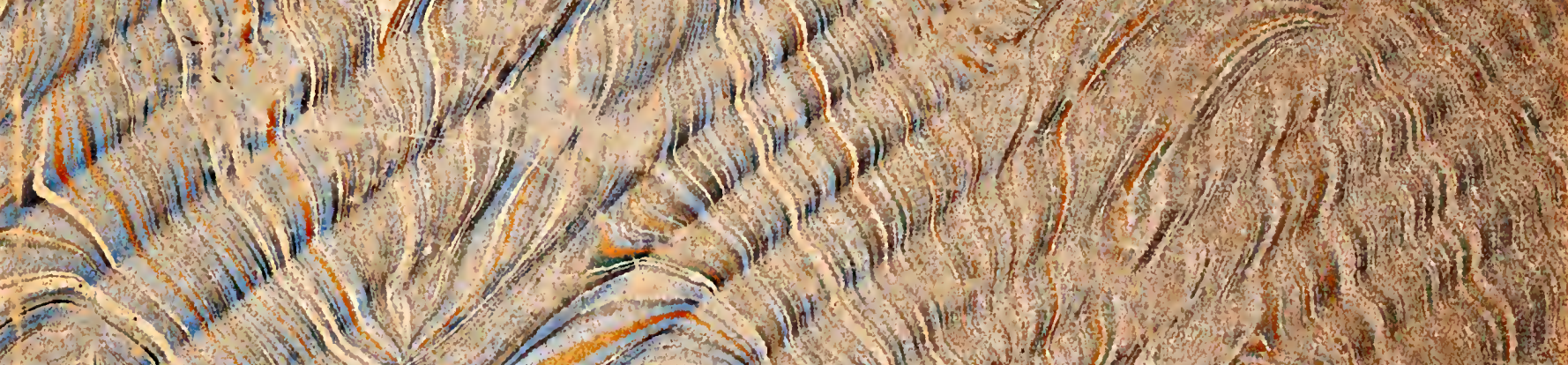

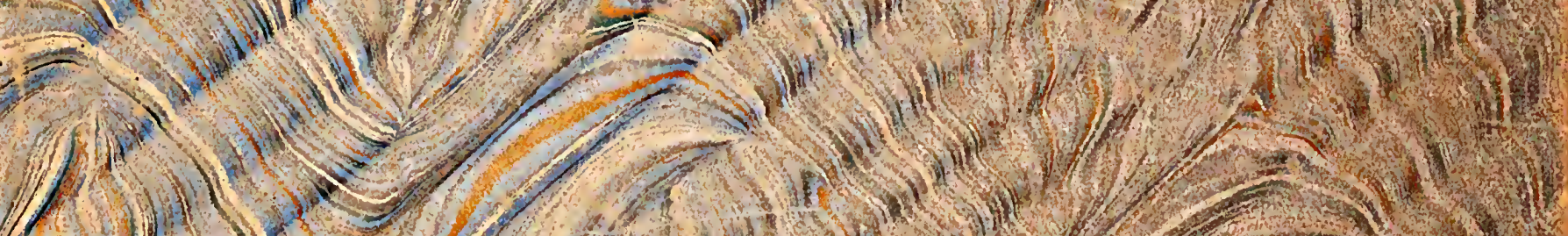
10 $1.1252^{2}$

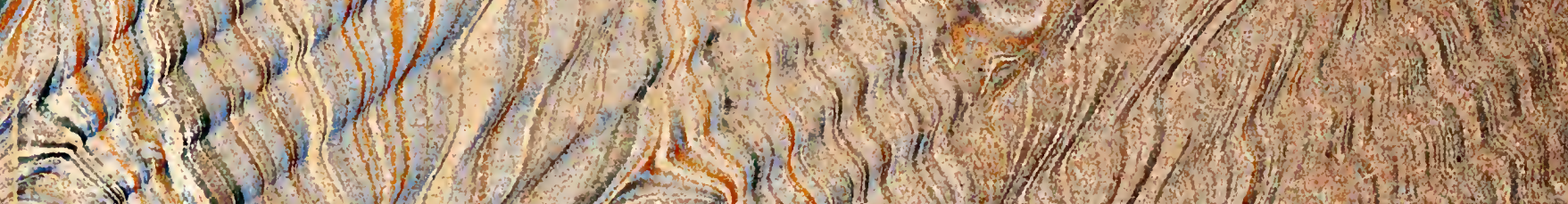

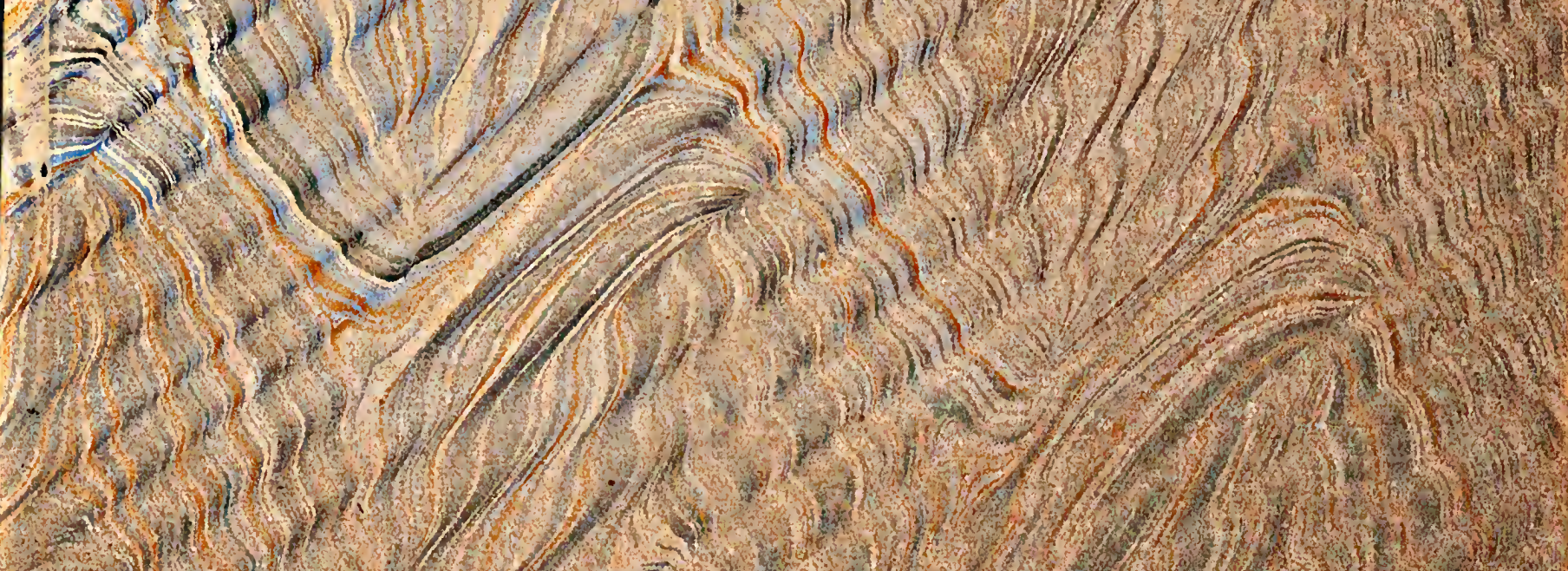




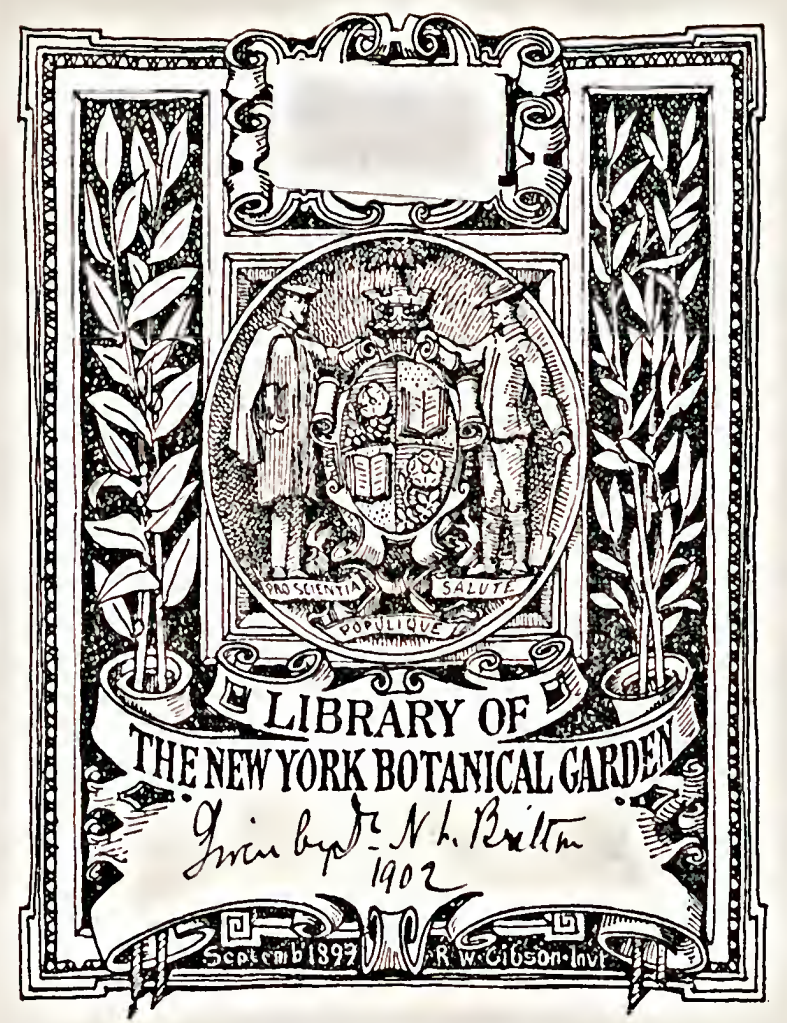


.<smiles>C1CC1</smiles> 



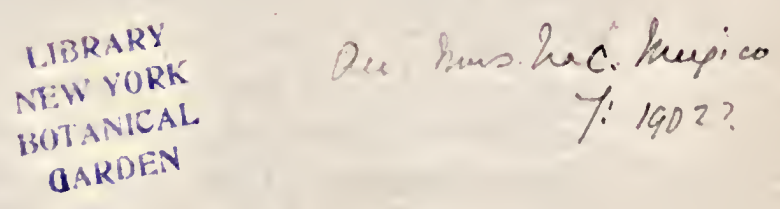

\section{LOS ZAPOTES DE HERNÁNDEZ.}

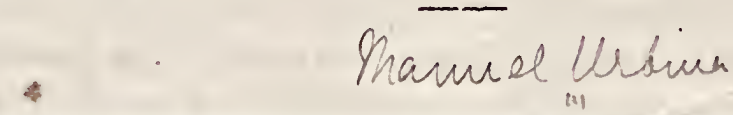

Hay un grupo determinado de frutos de plantas Mexicanas que los indígenas designaban con el nombre de Tzapotl, es decir, un fruto redondo, de pulpa blanda, de sabor dulce y con una $\delta$ varias semillas en su interior, generalmente duras; $\delta$ en otros términos, como se clasifica hoy, una baya carnosa, redonda y de sabor dulce, y que nosotros conocemos con el nombre de zapote.

Desde luego la palabra genérica es Tzapotl, y el nombre específico se establecía agregando la cualidad ó carácter que los distingue de las demás especies; por ejemplo:

Quauhtzapotl, tipo del grupo que quiere decir: árbol del zapote ó Tzapoquahuitl, sirviéndole de prefijo la palabra Tzapotl.

Las diversas especies eran distinguidas por varias de sus cualidades, y se diferenciaban de esta manera:

Por sus colores.

Iztactzapotl ó zapote blanco.

Tliltzapotl ó zapote negro, $\delta$ Totocuitlatzapotl ó zapote semejante por su pulpa negra al excremento de un ave.

Coztictzapotl ó zapote amarillo.

Por el aspecto de la superficie del fruto:

Illamatzapotl ó zapote de viejas, que presenta escamas más ó menos salientes figurando la cabeza de un negro.

Tezontzapoll, que presenta la cáscara semejante al tezontli, por su color.

Por la acción que produce en el cerebro:

Cochiztzapotl 6 zapote que produce sueño 0 embriaguez.

Por la preferencia que le dan las aves $\delta$ los jicotes $\delta$ abejas, que lo buscan como alimento:

Tototzapotl ó zapote de ave.

Xicotzapotl ó zapote de abeja 6 jicote.

Por el lugar donde crecen:

Atzapotl, zapote acuático ó que crece en el agua.

Tepetzapotl ó zapote de cerro.

Texaltzapotl ó zapote de lugares pedregosos.

Por la substancia que producen:

Chictzapotl 6 zapote que produce chictli ó chicle. 


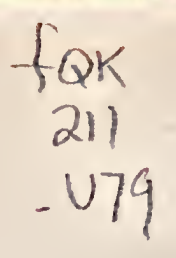

Por la semejanza con el fruto 6 planta del zapote:

Tzaponochtli 6 tuna semejante al zapote.

Tzatzapotic ó planta semejante al zapote.

Hay otros nombres como Matzapotl, nombre que daban á la chirimoya, debido tal vez al sabor tan dulce de esta fruta. Ate, ahate, con que los indios del Pánuco designaban á la $A$. squamosa, L. por la semejanza del fruto con un cono de pino. Chirimuyu, (1) que en lengua Quechua significa fruta de la semilla fría, porque lo es en sumo grado. Anona, derivado de Anon, s. Oviedo. "De allí, dice M. A. de Candolle,(2) "viene el nombre al Género Anona, que Linneo ha cambiado en Annona, porque no "quiso ningun nombre de las lenguas bárbaras, temiendo el juego de palabras.»

El'Sr. Lic. D. Cecilio A. Robelo (3) cree con justa razón que el vocablo es indígena de la América, bien sea de las Antillas ó de la Guayana.

M. de Martius (4) ha escrito páginas notables acerca de la historia de las anonas cultivadas en la América del Sur. Para él las Anona cherimolia, muricata, reticulata, squamosa, han sido importadas al Brasil, cultivadas primero en la vecindad de las habitaciones, y modificadas gradualmente por el cultivo. Por consideraciones históricas y filológicas este autor demuestra que ninguna de estas planlas es originaria de la India Oriental, sino que todas han sido igualmente introducidas en el Antiguo Continente después del descubrimiento de la América, y que las Antillas son su verdadera cuna.

Pongo á continuación los datos históricos para después hablar de las plantas de Hernández.

"Hay unos árboles (5) que se llaman Tzapotl, es liso, tiene la corteza verde, las hojas redondas, la madera blanca, blanda y liviana: hacen de ella sillas de caderas: la fruta de estos es como manzanas grandes: por fuera son verdes 6 amarillos, y por dentro blandos y blancos: son muy dulces, tienen tres 6 cuatro huesos blancos, y si se comen muchos dan cámaras. Hay otros zapotes que se llaman Cochiztezapotl, porque provocian á dormir, son como los de arriba, sino que son menores: hay otros como los de arriba, pero son muy grandes. Hay otros árboles que se llaman Atzapotl, son lisos, el fruto de estos se llama Atzaputl y son amarillos de dentro y fuera, son muy dulces, tiesos á manera de llema de huevo cocida, y tienen huesos de color castaño obscuro.

"Hay otros árboles que se llaman Xicotzapotl, llámanlos los españoles peruétanos, son muy dulces, y muy buenos de comer, hácense en tierra caliente. Hay otros árboles que se llaman Totolcuitlatzapotl: hácense en tierra caliente, la fruta de estos se llama de la misma manera, son grandes, por fuera son verdes, y por dentro negros, son muy dulces, y muy buenos de comer. Hay otros árboles que se llaman Tecontzaputl, son de la hechura y grandor del corazon de carnero, tienen la corteza áspera y tiesa, son colorados por dentro, son muy dulces, y muy buenos de comer, y los huesos negros muy lindos y relucientes. Hay otros árboles que se llaman Etzaputl, y la fruta Ceiotzapotl, son las anonas que tienen muchas pepitas negras como frisoles: tambien estos se llaman Quazhtzaputl.»

"Las frutas indudablemente indígenas de aquel país, (6) son: las ananas, que por parecerse en la forma exterior á la piña fué llamada así por los españoles; el mamey,

(1) Alcedo A., Dicc. Geogr. Hist. (Vocabulario.)

(2) M. A. de Candolle., Geogr. Bot., p. 861. Baillon., Hist. des Plant., I, p. 274.

(3) Robelo Cecilio A., Dicc. de Aztequismos.

(4) Fl. Bras., Anonac., p. 51. Baillon, loc. cit.

(5) Sahagún, Hist. Gen., ed Bust., III, p. $23 \overline{.}$.

(6) Clavijero, F. J., Hist. Ant. de México, I, 184t. Trad. por J. J. de Mora, pp. 13-14. 
la chirimoya, (1) la anona, la cabesa de negro, el zapote negro, el chico-zapote, el zapote blanco, el amarillo, el de Santo Domingo, el aguacate, la guayaba, el capulino, la guava ó cuajinicuil, la pitahaya, la papay'a, la guanabana, la nuez encarcelada, las ciruelas, los piñones, los dátiles, el chayote, el tilapo, el obo ú hobo, el nanche, el cacahuate, y otras cuya enumeracion no puede ser muy interesante á los lectores extranjeros. La descripcion de estas frutas se halla en las obras de Oviedo, de Acosta, de Hernández, de Laet, de Nieremberg, de Marcgrave, de Pison, de Barrere, de Sloane, de Jimenez, de Ulloa y de otros muchos naturalistas: así que sólo hablaré de algunas que no son muy conocidas en Europa.

"Todas las frutas mexicanas, comprendidas bajo el nombre genérico de tzapotl, son redondas ó se acercan á esta figura, y todas tienen dura la pepita (2). El zapote negro tiene la corteza verde, delicada, lisa, tierna, y la pulpa negra, carnuda, de sabor dulce, y á primera vista se parece á la casia (3). Los huesos que están dentro de la pulpa son chatos, negruzcos y de un tercio de pulgada de largo. Es perfectamente esférico y su diámetro es de una y media á cuatro ó cinco pulgadas. El árbol es mediano, muy cargado de hojas, y éstas son pequeñas. La pulpa, en helados ó cocida con azúcar y canela, es de un sabor delicadísimo.

«El zapote blanco, que por su virtud narcótica fué llamado en el antiguo México cochitzapotl, se asemeja algun tanto al negro, en el tamaño, en la figura y en el color de la corteza, aunque la del blanco es de un verde mas claro; pero la pulpa de este es mucho mas blanca y sabrosa que la de aquel. El hueso, que se cree venenoso, es grande, redondo, duro y blanco. El árbol es frondoso, mas alto que el del negro, y las hojas son tambien mayores. Ademas, el negro es propio de los climas calientes, $\mathrm{y}$ el blanco de los frios y templados.

-El chicozapote (llamado por los mexicanos chictzapotol), es de figura casi ó enteramente esférica, y tiene una y media ó dos pulgadas de diámetro. La corteza es blanquizca; la pulpa blanca, con visos de color de rosa; los huesos duros, negros y puntiagudos. De esta fruta, cuando está verde, se saca una leche glutinosa y fácil de condensarse. Los mexicanos llaman á esta sustancia chictli y los españoles chicle. Suelen masticarla los niños y las mugeres, y en Colima se hacen con ella pequeñas estatuas y figuras curiosas. (4) El chicozapote, cuando está en su madurez, es fruta de las mas esquisitas, y segun muchos europeos, superior á todas las del antiguo mundo. El árbol es de mediana altura; su madera bastante buena para construccion; las hojas son redondas y semejantes á las del naranjo en color y consistencia. Nace sin cultivo en las tierras calientes, y en algunas provincias forma bosques enteros que cubren espacios de diez y doce millas." (5)

Los zapotes de que habla son los siguientes:

(1) *Algunos escritores Europeos de las cosas de América confunden la chirimoya con la anona y con la guanabana; pero estas tres son especies diferentes, aunque entre las dos primeras hay alguna semejanza. Tampoco debe confundirse la anana con la anona, que difieren tanto entre sí, como el pepino y el melón. Mr. de Bomare, por el contrario, hace dos frutos distintos de la chirimoya y de la cherimolia, siendo así que este último nombre es una corrupcion del primero. El ate que algunos consideran como fruto enteramente diverso de la chirimoya, no es más que una de sus especies.

(2) «Las frutas comprendidas por los mexicanos bajo el nombre de Taapotl, son el maney tetzontzapotl, la chirimoya matzapotl, la anona quauhtzapotl, el zapote negro tliltzapotl, \&."

(3) "Gemelli dice que el zapote negro tiene el sabor de la casia; mas este es un error. Tambien dice que esta fruta verde es venenosa para los peces: es particular que un extranjero que residió diez meses en México, sea el único que haga mencion de esta circunstancia.»

(4) Gemelli aice que el chicle es una composicion artificial, no siendo otra cosa que la leche del fruto condensada al aire..

(5) Tomas Gage dice, entre otras grandes mentiras, que en el jardín de San Jasinto (hospicio 


\section{CAP. CXXXIV. \\ Atzapotl (1) ó ZAPOTE ACuAtico.}

* Acostumbran los mexicanos expresar en su lenguaje florido lleno de elegancia *y precision, las propiedades de las plantas, así como las aplicaciones y usos. De esta - manera llaman de un modo general á todos los frutos que tienen un sabor dulce "Tzapotl; Xocotl á los que son ácidos. Algunos géneros como Atzapotl o Tzapotl *acuático se dice porque proviene de árboles que crecen cerca de las aguas $\delta$ en lu«gares húmedos. Esta planta es un árbol grande con hojas parecidas á las del naaranjo, en número de siete, llevando cerca de la extremidad de los ramos flores blan"cas y estrelladas, las cuales producen un fruto casi redondo, grande y amarillo en *el interior, de sabor dulce, parece en cierto modo un alimento desagradable é indi«gesto, y excitando algunas veces calentura; en el interior se encuentra un hueso que «se usa especialmente como medicamento para las úlceras fagedénicas. El árbol se «llama Atzapotlquahuitl, y el fruto, como hemos dicho arriba Atzapotl, viene á ser a un melon pequeño por su tamaño y el suave olor que despide. Proviene de regiones *algo cálidas y cerca de los lugares húmedos y fértiles.»

Esta planta es designada con el nombre de zapote amarillo por el color de la pulpa, y borracho (ebrium) probablemente por el sopor que produce á los que lo toman, debiéndose rectificar ó confirmar el efecto hipnótico atribuído también á otros zapotes.

Se encuentra clasificada con el nombre de Lucuma salicifolia, Kunth. in H. B. Nov. Gen. et Sp. III, p. 241; DC. Prodr. viII, p. 171.

Achras salicifolia, Moc. et Sessé. Plant. Nov. Hisp. p. 49.

La descripción de esta planta fué hecha por el Sr. D. Vicente Cervantes, quien la comunicó á Bonpland, y puesta por Kunth en la obra titulada Nov. Gen. et Sp. t. III, p. 189; sin mencionar los caracteres del fruto, que probablemente no le dió Cervantes. El fruto es redondo, de tamaño variable de 10 á $12 \mathrm{~cm}$, con la cáscara de un color amarillo anaranjado cuando está maduro; la pulpa es de sabor dulce, aunque no tanto como la chirimoya; de un color amarillo-rojizo y más dura que ésta, con tres 6 cuatro huesos de $5 \mathrm{~cm}$. de largo por $2 \frac{1}{2}$ de ancho, iguales en forma á los de mamey.

\section{CAP. CXXXV.}

\section{Illamatzapotl (2) o ZAPOTE DE vIEJAS.}

«El Illamatzapotl, al cual los haitianos llaman Guanabano, es un árbol grande, con hojas parecidas á las del naranjo, cl fruto oblongo, grande, al principio verde, y por la madurez verde y amarillo, y en cuya superficie se distinguen á manera de es-

de los domínicos de Filipinas, situado en un arrabal de México, donde él residió algunos meses), habia árboles de esta especie. Es un error, porque la planta del chicozapole no se da en el Valle de México, ni en ningun país en que yela.»

(1) Hernz. ed. mat. 1, p. 177.

(2) Hernz. ed. mat. I, p. 178. 
camas delineadas; en el interior la pulpa es blanca y muy blanda; como alimento es sano, de sabor dulce y algo semejante al cacaoatl. Se da en regiones cálidas y fértiles como Cuernavaca, donde cuidamos de dibujar esta planta."

La planta que describe Hernández con el nombre de Zapote de viejas se encuentra clåsificada en los autores con el nombre de Anona muricata, Lins. Anona bonplandiana, H. B. K., y es conocida también con el nombre de Guanabano en las Antillas. El dibujo de la planta se encuentra en la edición romana (1), donde Hernández la menciona como un árbol de corteza cenicienta, fruto escamoso y semejante al cono de los pinos, por cuyo aspecto probablemente se le dio el nombre que lleva.

Esta anona se encuentra cultivada en las Antillas y en varios lugares de la República; ha sido bastante modificada en la forma, tamaño y aspecto del fruto, y los naturalistas han formado diversas especies con los nombres de $A$. reticulata, LinN.; A. esquamosa, Linn.; $A$. cinerea, Dunal; que todas deben reducirse á la especie primitiva, que es la $A$. muricata.

Baillon (2) trae también la figura y fruto de la $A$. muricata, donde están muy bien representadas las escamas del fruto. Las anonáceas son plantas que crecen en los paises calientes y han sido importadas al Brasil, siendo bastante modificadas por el cultivo. El Sr. M. de Martius (3) ha escrito páginas notables acerca de la historia de las anonas cultivadas en la América del Sur, y cree que todas han venido de las Antillas, donde está su verdadero origen.

Las anonas son en general arbustos elegantes, cultivados en casi todas las regiones calientes del globo; una de las más comunes es el fruto muy apreciado de la $A$. esquamosa, que es una grande baya aovada, casi globulosa, con carne blanda y blanca, y cáscara verdosa 6 amarillo-gris más resistente que la carne, y que presenta en la superficie pezones escamosos, obtusos y de figura romboidal. Se la ha comparado á una pera bien madura y aguanosa; con perfume más ó menos suave, semejante á la canela, y de un gusto muy agradable. Exprimiendo el jugo se puede preparar una bebida fermentada análoga á la cidra y de un sabor agradable; los firutos tiernos son astringentes, y las semillas irritantes. Según Royle se emplea el polvo de éstas, mezclado con el de garbanzo, para destruir toda clase de insectos como piojos, chinches y pulgas. En S. Andrés Tuxtla se prepara un aguardiente de zapote que es bastante apreciado.

\section{CAP. CXXXVI.}

\section{Tlaltzapotl (4) ó ZAPOTE NEGRO.}

"Es un árbol elevado, con hojas de naranjo, con el fruto de forma y tamaño de un melocoton mediano, al principio por fuera verde, mas tarde oscuro y algo negro, en el interior es de un intenso negro, por lo que se le da este nombre, blando y lleno de semillas, de un color amarillo oscuro; es comestible y de temperamento caliente; calma la saciedad, y de agradable sabor cuando está maduro, porque antes de la madurez es de naturaleza ardiente, sirve para curar la lepra, tiña, impétigo y sarna; esparcida en los rios mata los peces. Nace en regiones cálidas, principalmente en los huertos y lugares húmedos."

(1) Hernz. ed. rom., p. 444.

(2) Baillon, histoire des plantes, 1, p. 228.

(3) M. Martius, Fl. bras., Anonac., 51.

(t) Hernz. ed. mat. 1, p. 179. 
Esta planta se encuentra dibujada en la edición romana, (1) donde se dice que es un árbol fuerte, con el fruto semejante al membrillo y que lleva algunos surcos en la superficie; de color casi castaño. Allí se le da el nombre de Tlilzapotl, que parece más apropiado que el de la edición madrileña. Ha sido clasificada esta planta por los autores con el nombre de Diospyros ebenaster, Retz., y en la Flora Mexicana, por Mociño y Sessé; con el nombre de Diospyros tlilsapotl se describe el fruto como una baya globosa del tamaño de una manzana y rellena de una pulpa suave y negra. En cuanto á sus usos, dice que las bayas verdes son acres é irritantes y se usan para curar la lepra, tiña, impétigo y sarna. Arrojando pedacitos en los ríos mata á los peces.

Es muy apreciado este fruto en los usos económicos para preparar una conserva 0 ante de un gusto muy delicado, despojando al fruto de la cáscara y semillas y haciendo con la pulpa, azúcar, vino y canela, una mezcla de una consistencia blanda.

"Historia-Arbusto indígena de México, (2) según Clavijero, y el que se halla en Autlan, Cuernavaca y otros puntos de la República; pertenece á la familia de las Ebenáceas. Parece que Teofasto fué el primero que usó la voz Diospyros (Trigo de Júpiter) que se cree le dió al alpiste.

"Sinonimia:-Mexicano, Tliltzapotl (zapote negro); otomí, Bom-rza, Phonimir za; francés, Plaqueminier áfeuilles obtuses; español, zapote prieto; latín, Diospyros obtusifolia, WiLLD.

"Género.-Flores dioicas, cáliz 4-6 lobado 6 raramente (en la seccion Amuxi) hendido irregularmente. Corola tubulosa ó campanulada 4-6 fida, con lóbulos más cortos que el tubo, arrollados hacia la izquierda en la estivacion. Estambres de las flores masculinas 8-50, las más veces 16 insertos en la parte ínfima de la base de la corola, en el receptáculo, ó parte en uno y parte en otra, con filamentos más cortos que la antera, distintos, ó las más veces nacen pareados en la base con uno interior entónces, que es más largo que el otro, que es exterior; con anteras lineares-lanceoladas, dehiscentes lateralmente por medio de una hendidura longitudinal, con polen anchamente elipsoideo. Estambres en las flores femeninas más pocos, las más veces 8 con anteras impotentes. Ovario en los machos casi abortivo, en las hembras 4 , ó las más veces 8-locular 6 bien 10-12-locular. Estilos, 2-4, que nacen más 6 menos juntamente en la base, las más veces bilobulados en su ápice. Estigmas puntiformes. Óvulos solitarios en los lóculos, pendientes, anátropos. Baya globosa ú ovoidea, cubierta su base con el cáliz, frecuentemente acrecentado, 4-8-locular. Semillas oblongas, convexas en el dorso, más ó menos comprimidas lateralmente, borde interno recto, recorrido por una línea periférica de la base al vértice. Albumen cartilaginoso. Embrion axil, recto, en la semilla pendiente con cotiledones foliáceos. DC. Prodr. t. 8, p. 222.

"Adumbracion.-Dinspyros obtusifolia; ramulis glabris, follis oblongis obtusis, basi acutis et revolutis, glabris, supra nitidis, coriaceis, pedunculis femineis 3-7 floris petiolo subbrevioribus, pedicellis brevissimis, calyce 5-fido, campanulato, glabro, lobis ovatis, margine reflexis, corollâ apice constrictâ, 5- fidâ. Willd. sp. 4. p. 1112.

"Fruto.-De la forma de una naranja, algo deprimido en su base y vértice, de 3-4 pulgadas de diámetro, cubierto de una corteza delgada, lisa, que se rompe fácilmente, de un color verde obscuro. Su pulpa es negra como la de cañafístola, blanda como la manteca, de un sabor dulce agradable, remotamente nauseabundo y astringente; es muy abundante y lleva las semillas diseminadas, envueltas en un zurron semitrasparente y semicartilaginoso, siendo ellas de un color leonado obscuro, convexas en su dorso, comprimidas lateralmente y con un borde longitudinal obtuso opuesto al dorso.

(1) Hernz, ed. rom., p. 430.

(2) Oliva L., Dicc. Univ, de Hist. y de Geog., Ap. 11, pp. 1113-1114. 
«Propiedades.-Contienen azúcar, mucilago, tanino: son nutritivos y muy fácilmente digeridos, al grado que pueden concederse á muchos convalecientes; estando todavía verdes son tan corrosivos 6 calientes, segun Hernández, que curan la lepra, tiña, impétigo y sarna. Su corteza podría utilizarse como febrífuga; sus hojas como astringente. Tambien puede obtenerse aguardiente por la fermentacion del fruto ya maduro:»

\section{CAP. CXXXVII.}

\section{Tzatzapotic (1) o Planta semejante al Zapote.}

«Es una planta voluble, con hojas de Tzapotl, de donde le viene el nombre; carece de flor y fruto. A juicio de los indios el cocimiento de las hojas, agregandole Axim, tiene la virtud de fortificar á aquellos que están convalecientes de alguna enferme. dad: carece de olor y sabor notables; siendo de naturaleza fría es aprovechada para los febricitantes. Nace en las gargantas cálidas de Yautepec y en lugares húmedos de las montañas.»

Esta planta no he podido identificarla porque no ha llegado á mis manos.

\section{CAP. CXXXVIII.}

\section{Tezontzapotl $O$ ZAPOTE SEMEJANTE POR SU COLOR AL TEZONTLI.}

«El Tezontzapotl, (2) al que otros llaman Mamey, es un árbol grande, de troncos amarillos, con hojas de naranjo, llevando en su extremidad los últimos ramos con diez ú once hojas, las flores en los mismos troncos, de los cuales nacen despues unos frutos grandes en forma de huevo y color como dijimos ántes, semejante á la piedra de Tezontli, de donde le viene el nombre; al principio es duro y blanco y despues rojo, encerrando un gran hueso liso y lleno de una almendra. Es un fruto semejante por el sabor á la conserva de melocoton, y un alimento medianamente agradable; pero no siempre sano. El hueso encierra una almendra que suele agregarse á la bebida del Cacaoatl: tiene la virtud de conservar el color á los cabellos, untándolo para que no se partan y se conserven íntegros, así como á las llamadas xícaras y á todos los objetos de la misma especie, para afirmar el color. La corteza del hueso, machacada y bebida en vino, sirve para curar las afecciones del corazon y los cálculos de los riñones. Nace en las regiones cálidas.»

Esta planta, como dice Hernández, da un fruto grande en forma de huevo y semejante por su color á la piedra llamada tezontli; está clasificada con el nombre de $\mathrm{Lu}$ cuma mammosa, Gernt. Según Mociño y Sessé (3) le corresponde el nombre de Achras mammosa, y al hablar de sus usos dice: que la pulpa de los frutos es muy dulce y comestible, aunque menos sabrosa que los otros zapotes: la semilla, por su dureza y

(1) Hernz., ed. mat , I, p. 179.

(2) Hernz., ed. mat., I, p. 180.

(3) Moc. et Sessé, Pl. Nov. Hisp., p. 48. 
ser bastante lisa, es á propósito para planchar los lienzos. La almendra se tiene en México como un veneno mortal; en el estado de Oaxaca se tiene en gran estimación y se prepara una bebida muy espesa semejante al crémor, con la almendra machacada y mezclada á una masa formada de harina de maíz, cacao, azúcar y canela: se deleitan con ella los indios tomando esta bebida en sus fiestas solemnes, sobre todo en el adviento; se llama vulgarmente Choue, y la semilla ó almendra Pixtle.

De la almendra se extrae una substancia grasa de consistencia sólida; una verdadera manteca que llaman aceite de mamey y que se tiene en mucho aprecio untándolo en pomada para conservar el color á los cabellos y que no se partan. Hernández asegura también que sirve de mordente para fijar el color á las jícaras, además de la acción medicinal para las afecciones del corazón y cálculos de los riñones. En cuanto á la bebida que llama Caccioatl, no sé si será el Chue de Oaxaca ó alguna otra que se mezcle al cacao por tener el mismo principio que la almendra amarga, que según es sabido, se usa como condimento en la fabricación de los licores y dulces, aprovechando el perfume y sabor que dá la esencia. De todas maneras: puede aprovecharse la grasa, la esencia análoga á la de la almendra, y probablemente, si acaso tiene acción venenosa, será debida á la presencia del ácido cianídrico en pequeña cantidad.

El Dr. Fernando Altamirano publicó un trabajo acerca del árbol del mamey, (1) en el que además de dar la descripción, hizo un análisis de las almendras, que contienen los principios siguientes:

1. Manteca, conteniendo estearina y oleina, en la cantidad de un $45 \mathrm{p} \%$.

2. Amigdalina, que obtuvo por el método que indica Soubeirán.

3. Sinaptasa, que se demuestra por la formación del ácido prúsico.

4. Tanino.

5. Glucosa.

6. Albúmina.

7. Caseina.

8. Una substancia gomo-resinosa, de la que dice: que es probable sea una mezcla de caseina y materia extractiva. Hablando de sus usos, agrega que la grasa del mamey ha sido empleada hasta ahora como objeto de tocador; además indica que hay la creencia popular muy extendida, respecto de la grasa que se extrae de las semillas, de que produce efectos maravillosos, haciendo brotar el pelo donde ha desaparecido; cree que esta aplicación trae su origen probablemente de los aztecas, que usaban una preparación de la almendra, si no para hacer crecer el pelo, sí para conservarle su suavidad é impedir que se divida por el hongo que suele desarrollarse en su extremidad; es decir, evitar la formación de la orzuela.

Más adelante dice: que según el apreciable historiador, además de los usos que hemos dicho, las almendras las empleaban los indígenas para la bebida del chocolate, y les servían también para dar color á las jicaras.

En cuanto á la clasificación; dice que se conoce la Lucuma mammosa y la Bonplandii, y cree que el mamey de México, por algunos caracteres botánicos que describe, pueda ser diferente esta especie de las dos que hemos señalado.

(1) La Naturaleza, uI, p. 138. 


\section{CAP. CXXXIX.}

\section{Tototzapotl (1) ó ZaPoTe DE Ave.}

"Es un árbol grande y elegante á la vista, llevando hojas hirsutas y gruesas, semejantes á las del naranjo, pero sin embargo más acuminadas; el fruto pequeño, rojizo y de sabor agradable, sin que haya cosa digna de mencionarse.»

Pocos son los datos que nos da Hernández acerca de esta planta, que no está descrita en la edición romana, y por las noticias que he recogido de un pequeño zapote llamado Capiri, podría sospecharse fuera el Sideroxylon Mexicamum, Hemsl. Achras Capiri, Moc. et. Sessé. Lucuma? Capiri, A. DC.

Recibí el fruto del Capiri enviado por mi estimado amigo el Sr. Dr. D. Nicolás León, á quien le fué remitido del Distrito de Ario (Est. ${ }^{\circ}$ de Michoacán), donde es muy abundante el fruto, y como alimento, muy buscado por las aves, sobre todo por las Guacamayas, por cuyo motivo sospecho que pueda ser el Tototzapotl de Hernández.

Además, esta creencia parece justificada porque Alcedo (2) la menciona en su Vocabulario, y dice:

-Toto.-Ave pequeña de la Provincia de Chiapa, en el Reino de Guatemala: es "más chico que un pichon, y de color amarillo; pero las plumas de las alas son de un "hermoso verde, $\mathrm{y}$ los Indios las estiman tanto para sus adornos y sus galas, que te«xen primorosamente, que solo para utilizar de ellas cogen este páxaro, volviéndolo "á soltar luego que se las han quitado para que crie otras, por lo cual es entre ellos "delito capital el matarlo.»

Entiendo que esta ave llamada Toto pertenece probablemente á las Coas, y del género Trogon, que sọn tan abundantes en Michoacán y Querétaro, y que por el nombre mexicano de Tototl, aunque en general se aplica á toda clase de aves, aquí, tratándose de este zapote, se refiere especialmente al Trogon, de donde se deriva el nombre de Tototzapotl que consigna Hernández.

El fruto es una baya carnosa de forma redonda de 5- 6 centímetros, de un color amarillo, con pericarpio bastante grueso y lechoso, con una sola semilla del tamaño de una ciruela, de testa dura, lisa, semejante á la del mamey, con hilo lateral de forma ovalada, de cerca de un centímetro y colocado cerca de la base; albumen blanco y córneo, embrión ortótropo, cotiledoneos blancos, foliáceos, radícula muy pequeña. Esta planta, como dije antes, la recibí del Dr. Nicolás León con el fruto y las flores, y pude comparar sus caracteres genéricos y específicos con la descripción del Sr. Hemsley, $(3)$ en que manifiesta que el fruto le es desconocido, y cuyos caracteres describí antes para completar lo que faltaba relativo á éste.

Los Sres. Mociño y Sessé (4) traen muy buena descripción acerca de esta planta, que lleva el nombre de .Achras Capiri, y dicen: que es un árbol grande de más de cinco metros, al que los indigenas llaman Capiri, que lleva unos frutos redondos del tamaño de una pequeña guayaba: cuando están verdes escurren una leche muy viscosa, y maduros son amarillos, dulces y con un mucilago tenálz. Aseguran que en varios -lugares de Michoacán se comen crudos ó cocidos, sirviendo de alimento á los indios,

(1) Hernz., ed. mat., 1, p. 180.

(2) Alcedo A., Dicc. Geogr. Hist. (Vocabulario.)

(3) Hemsl., Biol. Centr. Am., Bot., II, p. 296.

(4) Moc. et Sessé, Pl. Nov. Hisp., p. 48, y Fl. Mex., p. st. 
aunque no muy sano. Por mi parte puedo afirmar que los frutos que recibí, ya maduros, son cie un sabor muy agradable, y que sujetando estas plantas al cultivo puede mejorarse mucho el tamaño y sabor de estos zapotes.

En resumen: estal especie, que era dudoso según DC., si pertenecía ó no al género Lucuma, queda yá rectificada su clasificación por el Sr. Hemsley, y con razón la refiere, aunque con pregunta, al género Sideroiylon. Por mi parte también queda confirmada, por tener albumen la semilla, mientras que el género Lacuma no lo tiene.

\section{CAP. CXL. \\ Tzapoquahuitl (1) ó Árbol del Zapote.}

«El Tzapoquahuitl es un árbol de tamaño mediano, llevando hojas grandes, seradas, con muchas venas bien marcadas, y acercándose algo por su forma á las del manzano. El cocimiento de la corteza, aplicado con algodon en las narices y oídos, calma los dolores de cabeza, de los dientes y de ios ojos. Nace en lugares templados de Huayacocotla (2) y otros lugares húmedos.»

El Tzapoquahuitl parece que debe referirse al Quauhtzapotl ó Anona que Hernández describe en el Cilp. CXLIII, si fuese indiferente decir Tzapoqualuitl ó Quauhtrapotl; me llama la atención que esta planta tenga las hojas serradas, que no las tiene la Anona, así como las venas bien marcadas, que podrían corresponder á otra especie que será identificada más tarde, pidiendo la planta del lugar que indica Hernández.

\section{CAP. CXLI.}

\section{Xicotzapotl (3) ó Zapote de ABEjA.}

"El Xicotzapotl es un árbol grande, con hojas de naranjo, más pequeñas; el fruto de forma, tamano y color igual al del níspero; sin embargo, por el sabor de manzanas algunos le llaman manzana apiana, cuando están medio podridos; encerrando tres ó cuatro huesos planos, acuminados, negros y brillantes y algunas veces blancos; sirviendo de un buen alimento, pero molesto y desagradable quando se toman más de dos. Nace en lugares montanosos y cultivado en algunos huertos.»

El chico zapote (4) es uno de los vegetales que se cultivan en el jardín de estudio de Hamma, cerca de Algeria. (Achras sapota, Lixw. Sapota achras, Mil...) El vegetal mencionado es un árbol grande, muy hermoso y constantemente verde, de las regiones intertropicales de la América; trasuda un jugo latescente muy viscoso, que se condensa en el aire y arde, esparciendo un olor bastante agradable. Los frutos son bayas carnosas, arredondadas ú ovales, de 10-12 lóculos monospermos, de los cuales cierto número aborta siempre. Las semillas son denticulares, elípticas, brillantes, de

(1) Hernz, ed. mat., 1, p. 1 s1.

(2) Municipio del partido de Chicontepec. Distrito de Tuxpan Est. de Pueblit.

(3) Hern\%, cd. mat., I, p. 181.

(4) M. Bernou, Farmacéutico. La Nituralezat, v, p. 312-322. Journal de Pharmacie et de Chimie, 883. 
color castaño obscuro, con un largo ombligo marginal: tienen la cubierta dura y la almendra blanca.

Casi todas las partes de este vegetal se utilizan. La corteza, como tónico y febrí. fugo. La madera es blanca, fibrosa, dura y bastante elástica: se emplea en carpintería y en las construcciones navales. Los frutos, conocidos con el nombre vulgar de Níspero de América, son frescos y muy sanos; la carne es suculenta, azucarada, y constituye uno de los manjares deliciosos de los habitantes de las Antillas y de la América meridional. En Francia actualmente son raros y cási no se les emplear; pero han sido muy estimados y los Españoles los usan aún. Las semillas se cree que son diuréticas.

El trabajo del Sr. M. Bernou, bastante escrupuloso y bien hecho, lo verificó únicámente en la corteza de esta planta; lo divide en tres partes: $10^{\circ}$ Historia y caracteres físicos. 2.0 Estudio histológico. 3.० Análisis químico. Como es bastante largo este trabajo tomo de él la parte relativa á la análisis de la corteza, que entre muchas substancias como el almidón, albúmina, \&., encontró un alcaloide que llama zapotina, materia grasa; un tanino que llama ácido zapotánico, y dos resinas.

El Sr. D. Pablo de la Llave (1) ha escrito un artículo acerca del Cosaguiico, plantá que se da en el lugar llamado Puente Chica, cantón de Córdoba (Est.o de Veracruz), cuyo nombre corresponde á un árbol corpulentísimo, admirable por su frondosidad y elevación, y que da un fruto semejante al zapote, por ser idéntica su organización al chico zapote, y señala como una especie nueva que denomina con el nombre de Achras cosagiuico. La única diferencia que se advierte es la del color: el zapotillo ó chico zapote es más ó menos rojo, y de melado claro el cosaguiico.

Desgraciadamente el Sr. D. Pablo de la Llave no describe la especie, de manera que no es posible aceptar la clasificación por no tener los caracteres á la vista.

En una nota del mismo artículo habla de la substancia llamada chicle, y dice lo siguiente: "El chicle es una sustancia que se encuentra en algunos zapotes y otros árboles. En el chico zapote, como una cera compacta y blanquísima cubre los huesos, y las mujeres del pueblo lo van recogiendo, formando de ellos bolas que tienen gusto en mascar, y aun saben darle cierto traquido, y su continua masticacion aumenta el flujo de la saliva. Cuando me hallaba en la hacienda del Corral acostumbraba banarme en una poza que llamaban del hule, porque estaba á la orilla de un árbol que se creía de esta especie; pero un campista inteligente me dijo que era una equivocacion, y me hizo conocer los verdaderos hules, asegurándome que el de la poza eral un amate, especie de ceiba, género abundantísimo en aquella tierra. Como siempre que podía hacía incisiones en los árboles, lo verifiqué en este amate del río y sálió mucha leche que ví con una especie de horror; por la idea que en general se tiene de que los jugos vegetales de esta naturaleza son cáusticos; pero al dia siguiente advertí que la parte del suelo en que había caido aquella sustancia estaba llena de avis. pas que la comían; volví á hacer otra incision, probé la leche y la hallé dulce. Con esto hice traer un plato hondo y lo llené hasta la tercera parte de su cavidad, de la referida leche, que al dia siguiente presentaba negruzca la superlicie, habiéndose adherido tan tenazmente á la vasija que no podía separarse. La cubrí toda con aguardiente hasta que rebosó en el plato, la tuve de esta suerte toda la noche, y al dia siguiente la encontré en los mismos términos. Escurrí en seguida muy bien el aguardiente, puse agua en su lugar, y al otro dia hallé la superficie blanquísima, toda la sustancia resquebrajada y desprendida del plato. Al estarla manejando me ocurrió que podía ser chicle; hice en efecto que lo mascasen, y resultó que era un verdadero

(1) Registro Trimestre, México, Febrero 6 de 1832; L.a Naturaleza, Apéndice, v'u, pp. 66-67. 
chicle, aunque no tan compacto como el del chico zapote. Yo no sé si se había hecho análisis químico de esta sustancia, que no disolvió ni el aguardiente ni el agua, únicos agentes que tenía á la mano. Por lo demás, estoy dudando si acaso el tal árbol es el Galactodendrum de que se habla en el Sinopsis-plantarum aequinotialium del Sr. Kunth.; y aumenta la sospecha el que el referido autor nos dice: que el hábito de la planta es el de los higos, género á que pertenecen las ceibas.»

La palabra cosagiiico creo que debe escribirse cozahuiz, que significa color amarillo, suponiendo que sea derivado de coztic, y entonces vendría á traducirse como zapote amarillo, perdiéndose por el uso la desinencia zapotl y quedando solo cozahuico.

\section{CAP. CXLII.}

\section{Cochiztzapotl (1) Ó ZAPOTE QUE PRODUCE SUEÑo.}

"Es un álbol grande y desaliñado, con hojas de naranjo escasas y ternadas; el tronco salpicado de manchas blancas, con flores amarillentas y medianas; el fruto, parecido por su forma y tamaño al membrillo, es llamado por los españoles zapote blanco: es comestible y de un sabor agradable, aunque no debe estimarse como alimento sano; el hueso que encierra es venenoso y mortífero. La corteza del árbol es seca y algo dulce, y con cierta amargura; las hojas, machacadas y aplicadas sobre los pezones de las nodrizas, sirven para curar la diarrea de los niños; la harina de los huesos, tostados ó quemados, sirve para curar las úlceras podridas, destruir la carne excedente en las úlceras fungosas, ó excitando la supuración produce carne nueva y abrevia la cicatrizacion; comidos los frutos concilian el sueño, de donde les viene el nombre. Nace en regiones cálidas y fiŕas.»

\section{Zapote Blanco.}

"Árbol indígena muy comun en Jalisco (2) y en otros lugares calientes y templados de la República, descrito por La Llav. et Lex., quienes dedicaron el género á D. Casimiro Gómez del Cardonal, militar de los otomíes.

«Sinonimia.-Mexicano: Cochiztzapotl (zapote que causa sueño), iztactzapotl (zapote blanco); Otomí: Ttasmurza, Ccast amurza; Español: zapote, zapote blanco, zapote borracho.

"Género.-Pentandria monoginia, Caliz 5-dentado, Corola de 5 pétalos, Filamentos insertos en el receptáculo, Baya pulposa pentasperma.-LA LLAV. et Lex.

"Descripcion.-Árbol mediano, de tronco císpero, rugoso, ramoso; hojas alternas pecioladas, peciolos de cosa de 4 pulgadas pinado-palmeados, con foliolos 5-7 peciolulados, peciolulos de cosa de media pulgada, foliolos lanceolados, lisos, enteros, subcoriáceos, verdes, lustrosos, más bajos de color al envés, de 3-4 pulgadas. Inflorescencia en racimo. Caliz corto, persistente 5-dentado. Corola de 5 pétalos blanquizcos, revueltos ó reflejados. Filamentos 5, aleznados, insertos en el receptáculo, casi

(1) Hernz., cd. mat, s, p. 1 s2.

(2) Oliva L., Dicc. Univ. de Hist. y de Geng., Ap., m, pp. 1113-1114. 
iguales á la corola. Anteras bilobuladas, semilunares, de costado una i otra. Germen hemisférico con estigma sentado oscuramente 5-partido. Pericarpio baya subglobosa llena de una pulpa sabrosísima.

"Fruto.-Un poco mayor que una manzana, ligeramente umbilicado á su base, de un color amarillo claro, ligeramente verdoso; presenta cinco costillas longitudinales poco notables; su epidermis es muy delgada, poco consistente; la corteza es granugienta y frágil. La pulpa, de un color algo mas bajo que el de la cáscara, es blanda, suave, jugosa, muy dulce, ligeramente acidulada, como vinosa; por la madurez desaparece su astrigencia y aspereza 6 austeridad. Las semillas 6 huesos son cinco, colorados alrededor de un eje ficticio, paralelos entre sí, y con el eje son triquetros; presentan un dorso convexo longitudinal y un borde obtuso que le es opuesto, dos faces laterales oblícuamente venosas, ásperas, blanquizcas; su consistencia es semileñosa, membranosa y fibrosa; contiene una almendra monocotiledonea? (sic).

"Usos.-Son alimenticios, fácilmente digeridos, aunque parecería revclaban una virtud narcótica; la almendra, según Hernández, es delctérea.

"Observacion.-El vegetal presenta numerosas afinidades con las zapotilleras, en cuya familia creo debe colocarse."

\section{CAP. CXLIII.}

\section{Quauhtzapotl (1) ó Avoss.}

"Lo que los mexicanos llaman Quauhtzapotl y los haitianos con el nombre vulgar de anona, es la misma planta que con igual nombre es conocida tambien entre los españoles de esta region; otros le llaman Texaltzapotl. Es un árbol grande y espacioso, coll hojas de naranjo, pero más angostas; las flores blancas y de tres puntas, semejantes por el aspecto y suave olor á las peras tempranas; el fruto manchado por fuera de rojo y verde, casi del tamaño de un melon, poco diferente del Illamatzapotl, y en el interior con semillas negras y pequeñas; se parece mucho á aquella célebre comida llamada manjar blanco, (2) tanto en la blandura y color, como en el sabor y dulzura, aunque no son iguales como alimento, porque esta fruta engendra ventosidades y no muy buen humor. Las pepitas ó semillas sirven de contra-veneno; pero se usan para curar las diarreas. Segun nos han asegurado, entre Sonsonate y la villa de San Salvador hay una especie de anona, de cuya semilla, si se toman diez 6 doce, sirve para purgar ligeramente y sin molestia la cólera y la flema. Nace en las regiones cálidas como la Isla Española y Cuernavaca, provincia de la Nueva España.»

"El árbol de la Chirimoya (3) es originario de México, crece, sobre todo, en las tierras calientes como Cuernavaca, Juchitlán y otras muchas. Los indios cultivan muchas variedades de este género porque de él sacan grandes utilidades. En el Brasil hacen uso de la raíz de la Anona asiática para teñir en rojo. La madera de la raíz de otra especie reune dos cualidades que la hacen apreciable: poco pesada y muy tenaz; y por esta razon en el imperio que acabo de citar la usaban los salvajes para fabricar escudos que los libraban de la accion de las flechas. En las Américas del Sur usan la corteza del tronco de la Anona palustris para curarse ciertas úlceras; y la madera

(1) Hernz., ed. mat., I, p. 182. Hern\%, ed. rom., p. 90, sine icone.

(2.) Plato de postre que se hace con leche, almendras, azúcar y harina de arroz.

(3) La Naturaleza, II, p. 198. 
de otra especie es tan suave como el corcho, y puede substituir á éste en sus usos. Sus hojas, maceradas en el aceite de olivo, sirven para preparar una cataplasma especialmente recomendada para la resolucion de algunos tumores. Su fruto, uno de los más delicados que podemos ofrecer en nuestras comidas, es buscado con afán por lo suave y agradable de su pulpa; y por último, sus semillas gozan de gran reputacion como emeto-catárticas, y sobre todo, como insecticidas. Para el primer uso toman una ó dos semillas, segun la edad del paciente, las hacèn sufrir una ligera torrefaccion, $\mathrm{y}$ despues de separar el perispermo duro que las cubre, las administran, haciendo una especie de emulsion con el agua ó leche. Para el segundo uso toman cinco ó seis semillas, las machacan y mezclan con manteca para aplicarlas sobre las partes del cuerpo que quieren librarse de la presencia de los parásitos. El nombre vulgar es el de Chirimoya, que probablente es derivado de la palabra Chirimuya, que en lengua quiché significa fruto de semilla fría, y en mexicano Cuauhtzapotl.»

El Sr. D. Carlos Garza Cortina escribió un trabajo del cual tomo estos datos; analizó las semillas de Chirimoya, y reconoció las substancias siguientes:

Azúcar, goma, albúmina y materia estractiva, un aceite y una resina. A esta última deben atribuírsele las propiedades emeto-catárticas de la semilla.

Hảbiendo tomado 15 centígramos de dicha resina el Sr. Garza Cortina, al cabo de un cuarto de hora se encontraba en un estado alarmante, siendo los síntomas principales los vómitos, la dilatación de la pupila, la sequedad de la boca y el ardor en la garganta. Y cuyos síntomas fueron calmados con la administración del opio, para quitar los dolores, y con la belladona, para contener los vómitos. Habiendo sido administrada la belladona, por la semejanza de los síntomas que produce esta substancia, según el axioma "similia cum similibus curantur.» Esta planta corresponde á la Anona cherimolia, MrLL.

\section{CAP. CXLIV.}

\section{Quauhtzapotl secunda (1) ó ZAPOTE DE MONTAÑA.}

"Es un árbol grande con hojas semejantes á las del naranjo; sin embargo, más pequeñas, obtusas, y muchas nervaduras bien marcadas; el fruto, por su forma y naturaleza, muy semejante al Xicotzapotl, pero es más grande. Nace en lugares cálidos y montañosos de Colima, pero por el cultivo se encuentra ya en los huertos y jardines.»

No he tenido oportunidad de examinar esta planta, de la que no hace mención la edición romana; tampoco se encuentra el nombre de tepezapotl en ninguna de las dos ediciones. Sólo el nombre de Zapote de montaña me hace creer que se trata aquí de la Ternstromia tepezapote, $\mathrm{CH}_{\text {. }}$ et SchL.

En la flora mexicana los Sres. Mociño y Sessé hablan de tres especies de Ternstromia: la primera, de Puerto Rico; la segunda, de Cuernavaca; y la tercera, de Toluca. En las plantas de Nueva España sólo mencionan la Ternstrœmia meridionalis, Mut., llamándome la atención que no la hayan conocido con el nombre de Tepezapo$t e$, ni digan nada acerca de los caracteres del fruto, y si es comestible ó no.

El Dr. Leonardo Oliva en su obra (2) habla de una planta conocida como «hierba del cura," que se usa como vulneraria, y la trae clasificada como Ternstromia alta- 
mirania, Schiede. El Sr. Alfonso Herrera á su vez copia en la Farmacopea mexicana la misma denominación, sin citar ninguno de los dos dónde fué descrita por Schiede, é ignoro yo también en qué publicación se halla. Supongo que fué dedicada por el Sr. Schiede á mi abuelo materno el Sr. Dr. D. Manuel Altamirano, botánico distinguido, quien clasificó muchas plantas mexicanas, y cuyos escritos, por desgracia, se perdieron; pero entiendo que conoció y trátó al Sr. Altamirano el año de 1836, que fué la época en que el Sr. Schicde estuvo en México.

Examinando las diversas especies mexicanas del géncro Ternstromia, encuentro que una misma cspecie ha recibido diversos nombres, scgún el testimonio de Decandolle y Hemsley, que todos corresponden á la Ternstromia tepezapote, CH. ct Schl., y que hoy está comprendida en el género Dupinia, s. Durand; es decir, que debe llitmarse Dupinia tepezapote, Durand.

En el Brasil se conoce también como "hierba del cura (1) la T. sylvatica, Cr. ct Schl., que se encuentra en varios lugares de México, y en mi opinión es la misma que llamamos Tepezapote.

\section{CAP. CXLV.}

\section{Tzapotl haitiano (2) ó MaMey.}

"Es un árbol grande, de largas hojas, elegante y de vista agradable; con el fruto semejante al membrillo, de color amarillo, aunque en cierto modo es un alimento des. agradable é indigesto, y contiene dos ó tres semillas grandes. Nace en lugares cálidos como la Isla de Haití, de donde fué trasladado á la Nueva España, debido al cm. peño del dicstro $\mathrm{y}$ hábil guerrero Bernardo del Castillo, cn cuyo célebre huerto de Cuernavaca procuramos dibujarlo.»

El zapote de Haití ó mamey que menciona aquí Hernández desde lucgo se ve que no es planta mexicana, sino que fué trasladada á Cuernavaca para su cultivo, y por lo mismo corresponde á la Lucuma domingensis, GæRTN., ó sea el zapote de Santo Domingo.

\section{CAP. LXXXIII.}

\section{Ahate panucina, ó Quauhtzapotl, ó Anona. (3)}

"Es un árbol pequeño con hojas de limon, pero mas largas; olor de lima ó cidra; seco y caliente en tercer grado; con el tallo rojo y un fruto excelente, que al exterior es parecido al Matzatli, y al interior á una Anona, de donde toma su nombre; es dulce, y su tamaño no excede al de una granada, aunque prontamente se pudre. Nace en cl Pánuco, donde se ticne en gran estimacion, y en Cuernavaca, donde comienza á cultivarse este árbol.»

En Cuba, Filipinas y cl Brasil (4) es conocida esta planta con los nombres de Ates,

(1) Baillon, Hist. des plant., IV, p. 2:3l.

(2) Hernz., ed. mat., I, p. 184.

(3) Hernz, cd mat., I, p. 45.

(4) Colmeiro M., Dicc. Plant., p. 26. 
Ahates, que según Colmeiro, es la Anona squamosa, Lins., y la Atta de la Isla de Santo Domingo, la Anona obtusifolia, Tuss.

La edición romana trae una buena figura, y dice lo siguiente: (1) "Ahate ó Ate de Panucho, 6 fruto semejante al Tzypipatli de los mexicanos. Es un árbol con hojas parecidas a las del naranjo; el fruto es azul al principio, más tarde negro, imitando por el lustre al fierro pulido; redondo á pesar de sus escamas: por su figura se parece al cono de un pino; los ramos son de un color castaño y las hojas del color del nogal.» Más adelante, en la pág. 454, agrega á lo expuesto antes, que los pánucos le llaman Ahute por parecerse en su forma globosa al cono de los pinos.

La figura y descripción revelan desde luego que se trata de la Anona squamosa, Linn., comprobado con la opinión de Colmeiro.

\section{CAP. CXL.}

\section{Tempixquiztli (2) Ó Medicina astringente para la Boca.}

"Árbol grande y espinoso, llevando hojas casi redondas de la forma y tamaño de las del naranjo, pero blanquizcas é hirsutas en el envés; el fruto poco diferente de la nuez ó ciruela: glutinoso y de sabor agradable; las flores, de un blanco amarillento, delicadas y distribuidas en los ramos de tal modo, que nacen dos en ambos lados en el nacimiento de las hojas. El cocimiento de las hojas, instilado en las narices y en los oídos, ó las mismas hojas calentadas en la ceniza y aplicadas á los dientes, calman todos los dolores y afirman las encías. Proviene de los lugares cálidos de Teocaltzinco y Meztitlán, cerca de las colinas.»

Por los caracteres que describe Hernández á esta planta, como por las aplicaciones médicas que recomienda, debe clasificarse como Bumelia subsessiliflora, HensL. (3)

\section{CAP. CIX. \\ Tempixquiztli.(4)}

"Esta planta se distingue de la que describimos en el libro primero con el mismo nombre, porque no lleva espinas y las hojas, que son anchas, ni son hirsutas, ni ásperas en el envés; además carece de flor y fruto, que en todo lo demás es idéntica. El jugo de la corteza es de un sabor casi nulo, siendo de naturaleza fría y seca, sirve para curar las úlceras y ardores de la boca. Proviene de lugares cálidos y montañosos.»

Con el nombre de Tempixquiztli recibí del Sr. Nicolás Rojano, el día 8 de Mayo de 1901, la planta, flores y fruto procedentes de Tehuacán, y examinadas convenientemente puedo asegurar que pertenecen á la Bumelia late-virens, HemsL., aunque Hernández describe esta planta diciendo que es igual á la que describió en el libro primero, que es también del género Bumelia, y dice que difiere únicamente en que

(1) Hernz., ed. rom., p. 348.

(2) Hernz., ed mat., s, p. 77.

(3) Biol. Centr. Am., Bot., Il, p. 299.

(4) Hernz., ed mat., II, p. 197. 
no lleva espinas ni las hojas son hirsutas ni ásperas en el envés; agregando que carece de flor y fruto, lo que me resisto á creer por pertenecer, como dije antes, al género $\mathrm{Bl}$ melia, y si fuese así, debe clasificarse por los caracteres del fruto, que es del tamaño de una aceituna, de color verde cuando está tierno, de pericarpio grueso, conteniendo una semilla de forma oblonga de centímetro y medio de largo por un centímetro de ancho, de texta dura, lisa y brillante como la del mamey, con hilo basilar casi redondo, cotiledones gruesos, ovales, radícula pequeña, albumen nulo.

Los Sres. Mociño y Sessé (1) describen esta planta con el nombre de Achras olivacea, y dicen que es un árbol de 15 pies con hojas alternas oblongo-lanceoladas, acuminadas, íntegras y lampiñas, y al hablar del fruto lo describe como una drupa del tamaño de una ciruela, que habita en los montes totonacos y florece en Agosto.

Hablando de sus usos dice que las bayas verdes se toman como las aceitunas, encurtidas con vinagre y sal, y se llaman entonces Tempeschitle (sic) ó Tempextles, y cuando están ya maduras Tilzapotl (sic).

El Sr. Nicolás Rojano me dice que en Tehuacán llaman tilapos al fruto ya maduro, que es comestible dulce y viscoso, y tempixtles al fruto verde que se toma como las aceitunas.

Por estos datos se ve que la planta Tempixquiztli ó medicina astringente para la boca, era usada entre los indígenas para curar las enfermedades de las encías y modificar las ulceraciones por su acción astringente; lo mismo que el cocimiento de las hojas para curar las inflamaciones, instilándolo en las narices y en los oídos; hechos que no repugnan por estar comprobados por la experiencia, y además, porque los jugos lechosos generalmente son aplicados para modificar toda clase de úlceras.

Esta planta debe quedar clasificada con el nombre de Bumelia late-virens, HemsL.; Achras olivacea, Moc. et Sessé.

\section{ZAPOTES DE OTROS AUTORES.}

Los Sres. Mociño y Sessé en la Flora Mexicana mencionan el Achras olivacea, que es:

\section{De México.}

Achras olivacea...... Bumelia late-virens, HemsL.

" capiri....... Sideroxylon mexicamum, Hemsl.

" duplicata..... Sideroxylon?

De Puerto Rico.

Achras acana.

" nitida.

La A. duplicata, por los caracteres generales que le da la Flora, sospecho que es un Sideroxylon, hecho que se rectificará más tarde con el examen de la semilla, que no tengo á la vista para averiguar si tiene ó no albumen.

(1) Fl. Mex., p. 8t, ed. Fom., 1893. 
En las plantas de N. España los Sres. Mociño y Sessé señalan los siguientes:

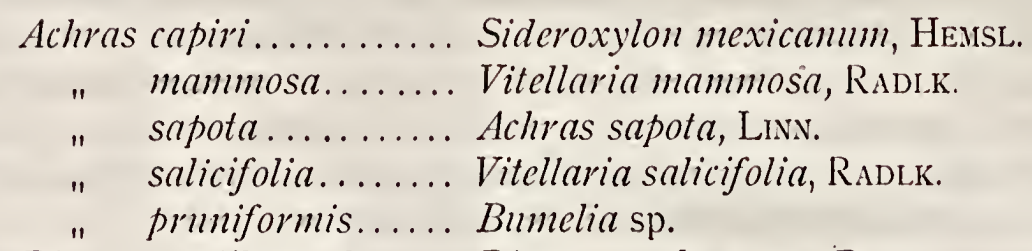

Diospyros tlilzapotl..... Diospyros ebenaster, Retz.

\section{ANONÁCEAS.}

En la flora Mexicana:

Anona biflora...... $\}$ De Puerto Rico.

A. fruticosa....... Del Espinal.

Los Sres. Mociño y Sessé, al hablar de esta última, dicen que es un fruto del tamaño de una ciruela, muy dulce. Yo no lo he visto; tal vez se refiera á una Bumelia ó Sideroxylon.

En las plantas de Nueva España:

Anona muricata...... De México.

" squamosa.... id.

" reticulata..... id.

" glabra...... id.

Todas son admitidas.

El Dr. Leonardo Oliva (1) señala un Tepezapote con el nombre de Pircunia dioi$c a$, DC., cuya planta pertenece á la familia de las Fitolacáceas: corresponde á la Phy. tolacca dioica, Lisw., planta que no es nuestra y que no debe considerarse como Tepezapote.

Señala también el Tempixque, dando cste nombre al Lucuma capiri, que corresponde hoy al Sideroxylon mexicanum.

El Sr. A. Gray (2) dió á conocer un fruto comestible, que es una baya de más de una pulgada de tamaño, semilla ovalada y albuminosa muy parecida a! Lucuma? $f e$ rruginea, cuyos frutos son producidos por grandes árboles de 25 pies de altura y 2-3 pies de diámetro encontrados en la Barranca (Est. de Jalisco), y que fué clasificado con el nombre de Sideroxylon petiolare, A. Gray.

El Sr.S. Watson (3) señala también un pequeño árbol de 5-8 pics de altura y algunas veces de un pie de diámetro: la madera de este árbol es sumamente dura y pucde ser usada en las construcciones; como combustible, al quemarse produce mucho humo. Desgraciadamente cl fruto no fué colectado; pero entiendo que ha de ser comestible como el Tempixque: fué encontrado en las cañadas profundas, cerca de la

(1) La Naturaleza, v, p. 129.

(2) Proc. Am. Acad, xxıI, p. 431.

(3) Proc. Am. Acad., xxiv, p. 59. 
bahía de los Ángeles (Baja California), y debido al color blanco tomentoso de sus hojas fué clasificado con el nombre de Sideroxylon leucophyllum, Wats.

El inteligente naturalista J. N. Rose (1) encontró un zapote amarillo, cuya especie fué colectada por Humboldt y Bonpland cerca de Acapulco (Est. de Guerrero), y fué clasificada y descrita por Kunt como una Hirtella, siendo entonces desconocido el fruto. Mr. Hemslcy refiere también á esta especie una planta colectada por Linden en Tabasco. Esta especic ha sido recientemente recogida por el Dr. E. Palmer, pero solamente en flor. Mr. Rose agrega que ha colectado varios ejemplares cerca de Acaponeta (Territorio de Tepic), de donde con toda seguridad es nativa, y es muy conocida con el nombre de zapote. El Dr. Palmer dice que en Acapulco es conocida como zapote amarillo: el fruto es aparentemente comestible, pero no se encuentra ninguno en el mercado. El fruto es oblongo, casi de tres pulgadas de largo, de un color amarillo y con la cáscara rojiza y verrugosa; contiene una semilla grande que está fija en la base. Parece ser muy común en las costas occidentales de México, donde es evidentemente nativa. Crece á la altura de 10-25 pies. Fué determinada por el Sr. Rose con el nombre de Couepia polyandra, (H. B. K.) Rose. El mesocarpo de las Couepias es comestible en las Antillas, principalmente en la Guayana y en el Brasil.

Más adelante dice que el nombre de zapote amarillo se da también á la Zapota elongata. Señala con el nombre de Zapotillo amarillo la Cratceva sp., que viene á ser un zapute falso. (2)

En Colima (3) existe un árbol de copa bastante cxtendida, el tronco de un pie de diámetro y el fruto lampiño, que ha sido señalado por Mr. Rose con el nombre de $\mathrm{Bu}$ melia arborescens, y una especie nueva de Lucuma, aun no clasificada, que es un pequeño arbusto de 10 pies de altura y fiuto también desconocido, que fué colectado en Manzanillo (Est. de Colima.)

El Zapotito de San Juan, Bunchosic lanceolata, Turcz., que pertenece á la familia de las Malpigiáceas, y que no debe considerarse como un verdadero zapote. (4)

El Comíngalo, (5) fruto llamado así y que pertenece, según Oliva, á la Lucuma spharocarpa, A. DC.

Hay otros nombres como el de Níspero dado en Nicaragua y el Perú al Chico zapote.

El Dr. José Ramírez (6) clasificó una nueva especie: la Casimiroa pubescens, ó Zapote de rata, que fué colectada por el Dr. Fernando Altamirano en la Sierra Gorda (Est. de Querétaro). Al hablar del fruto dice: que es una baya globosa, deprimida, semejante á una manzana, vellosa y aterciopelada, de $4 \mathrm{~cm}$. de diámetro y $21 / 2$ de altura; de pulpa blanca y con 566 semillas como el zapote blanco: presume que no es comestible.

(1) Contr. U. S. Nat. Herb., v, pp. 196-216.

(2) Contr. U. S. Nat. Herb., I, p. 301.

(3) Contr. U. S. Nat. Herb., I, p. 339.

(4) Herrera A., La Naturaleza, vi, p. 354.

(5) Oliva L., La Naturaleza, v, p. 97.

(6) Anal. Inst. Med. Nal. II, p. 18; La Naturaleza, serie $2 .{ }^{a}, 11$, p. 49.2. 


\section{RESUMEN.}

La mayor parte de las Anonáceas son estimadas en los países calientes por sus cortezas aromáticas, sus flores olorosas, y por sus frutos principalmente.

Los frutos son por lo general carnosos é indehiscentes: son bayas polyspermasé independientes, $\sigma$ monospermas y soldadas entre sí. Las semillas, frecuentemente envueltas en un arilo, contienen un pequeño embrión en un albumen córneo y ruminado; es decir, con hendeduras más ó menos profundas. Las más apreciadas entre nosotros son las Anonas, Ilamas y Chirimoyas, que son un buen alimento si están maduras, y usadas como medicina cuando están verdes.

El grupo de los zapotes mexicanos comprende principalmente la familia de las Zapotáceas y Anonáceas, y algunas plantas de otras familias que por cl fruto semejante al zapote llevan este nombre; pero cuyo carácter consiste, como dije al principio, en una baya carnosa, redonda, de sabor dulce y que contiene semillas duras que llamaron zapote y que servía de tipo para su clasificación. También aparece la coincidencia que el çarácter del fruto pertenece á familias que tienen entre sí grandes afinidades.

Las Zapotáceas son generalmente plantas lampiñas, de hojas alternas, casi siempre enteras y generalmente lustrosas; las flores ocupan casi siempre la axila de las hojas caídas, desprendiendo las más reces un perfume suave cuando se les hace hervir, muy rara vez fétido; los órganos vegetativos tiñen en rojo ó negro el agua hirviente.

Sus maderas son muy apreciadas por sus colores y dibujos; pesadás, resistentes, muy propias para la construcción y ebanistería, como las del chico zapote, mamey, tempixtle, capiri, \&. El zapote prieto, cuya madera es tan estimada que produce en su duramen el ébano, tan notable por su color negro, y de donde saca el nombre la ebanistería; la no menos estimada madera de fierro, que en griego significa Sideroxylon, de la cual tenemos tres especies. Algunas de ellas, como las Bumelias, sirven para teñir lienzos y cuero, probablemente por el tanino que contienen. Sus frutos, tan apreciados como deliciosos, sirven de alimento cuando están maduros, siendo debido su sabor agradable á la gran cantidad de azúcar que contienen y á la suavidad de su pulpa que ha sido tan modificada por el cultivo de un gran número de años, pues la mayor parte son cultivados y pocos son silvestres. Los frutos verdes no son comestibles, pero gozan de una acción medicinal, sea, como se sabe vulgarmente, para producir el sueño ó embriaguez, y alguna otra que no ha sido estudiada y que importa conocerla.

Sus semillas ó almendras, como las del mamey, chico zapote, zapote prieto, contienen substancias grasas que generalmente son mantecas, y pueden aprovecharse para el alumbrado ó la fabricación del jabón, ó en pomadas para el tocador, como se hace con el aceite de mamey. Además, contienen ácido cianhídrico y una esencia parecida á la de la almendra amarga, que puede servir por su acción médica como condimento, como se emplea en las almendras amargas. Las del chico zapote han sido empleadas en emulsión, en número de seis como diuréticas, y para curar la disuria, estranguria, 
\&., según dice el Dr. Oliva, (1) y si el número es mayor de doce, son eméticas, causan crueles dolores y peligra el enfermo. Recomienda por sus propiedades béquicas y dulcificantes, por el azúcar que contiene, á los frutos del chico zapote, mamey y zapote prieto.

El producto más importante que puede y debe explotarse, es la leche que contienen la mayor parte de estos árboles, y que al aire se condensa formando lágrimas 0 masas de un blanco lechoso, y que es conocida entre nosotros con el nombre de chicle.

El chicle es la substancia conocida en el comercio europeo con el nombre de Gutapercha, cuya etimología es: Gutta, goma; Percha, Sumatra: Goma de Sumatra, nombre que le fué dado por los indígenas del Archipiélago Malayo. La primera planta explotada para la extracción de este producto en las islas de la Sonda, (2) ha sido la Isonandra gutta, Hook., de las Zapotáceas, de la cual los Malayos hacían desde tiempos muy remotos diversos objetos, tales como mangos de cuchillo, de hacha, calzados, telas impermeables, instrumentos diversos y multitud de utensilios domésticos. Fué introducida en Europa en 1843 y desde entonces ha adquirido una importancia industrial considerable, siendo importada de Singapore y de la China. No baja de 50,000 kilogramos al año solamente en Francia.

El procedimiento primitivo (3) para su extracción, usado por los Malayos, consis. tía en derribar el árbol que se había escogido, despojándole de sus ramas; pero como las hojas siguen desempeñando sus funciones, quitan al tronco el latex que encierra la guta: después que el tronco quedaba derribado, practicaban sobre él incisiones paralelas é inclinadas, separando la corteza en colgajos. De esta manera cortaban los vasos lacticíferos dejando escapar su contenido, que se derramaba en las cavidades practicadas, donde se coagulaba instantáneamente. Para recoger esta materia se le sumerge en agua hirviendo, amasándola y golpeándole con mazos de madera; después se forman panes que se entregan al comerciante chino, intermediario con el comercio europeo.

Por este método el consumo de la guta es considerable, y se hace explotando los árboles de grandes dimensiones, que tienen 30 años y miden 90 centímetros de circunferencia casi al nivel del suelo. Los retoños de los árboles antiguamente derribados pueden ser explotados á los 14615 años: cada árbol produce como máximum de 230 á 265 gramos de guta, mientras que las estacas de 15 años producen sólo 90 gramos.

Otro procedimiento que ha sido recomendado es el de M. Jungfleisch, que consiste en extraerlo de las hojas, de las yemas tiernas y de los ramos de 2 años, tomando estos ejemplares secos y tratándolos por la toluena, que es el mejor disolvente, el que ofrece más ventaja, obteniéndose cantidades casi constantes de guta. Por esta operación se consigue no derribar el árbol, y por medio de una poda inteligente de ramos y hojas se extrae de ellos dicha substancia sin perjudicar la vida del árbol. Se ha llegado á obtener por los disolventes de 1,000 á 1,100 gramos, mientras que el árbol derribado no da más que 265 gramos. La explotación primitiva todavía se hace con la mayor actividad en Java, en Borneo, en Sumatra y en la India.

El procedimiento moderno de explotación ha substituído al primitivo, y se practica exactamente lo mismo que se acostumbra para extraer el caucho, haciendo incisiones al derredor del tronco para recoger el latex: no solamente se cosecha así en mayor cantidad, sino que puede repetirse la operación durante muchos años sobre el mismo árbol.

Recogido el latex y abandonado al aire se coagula en una masa esponjosa que se

(1) Oliva L., Lecc, Farm., I, pp. 106-313.

(2) J. Vesque, Bot. Agric., p. 856.

(3) A. E. Brehm., Les Plantes, 1I, p. 225. 
petrifica y se comprime en panes de 10 á 20 kilogramos. La materia bruta, mezclada con substancias extrañas, es reblandecida en el agua caliente y sometida á una nueva compresión.

La Gutapercha es naturalmente blanca; pero según las cantidades de impurezas que contiene cambia el tinte en amarillo ó rojo. Es insípida, de un olor agradable y especial; es tenaz, flexible, mucho menos elástica que el caucho y se corta con facilidad con el cuchillo. Se disuelve fácilmente en el sulfuro de carbono y en la bencina, muy poco soluble en el alcohol y en el éter, é insoluble en el agua.

La Gutapercha del comercio encierra de 75 á 82 por ciento de guita pura, materia blanca y extensible, fusible á los 100 grados y que contiene dos resinas, una blanca cristalizable, y la otra amarilla amorfa, y tal vez algunas otras; un ácido orgánico soluble en el agua, con una materia extractiva igualmente soluble en el agua; aceite esencial, materias colorantes, caseina, y cerca de 5 por ciento de cenizas.

Cuando èstá vulcanizada la Gutapercha conserva su solidez á temperaturas más elevadas que al estado natural.

La plasticidad de esta materia á los 50 grados permite darle todas las formas imaginables: se hacen correas de transmisión de movimientos en las máquinas, hilos; cuerdas, cintas para formar ligaduras tenaces que resisten perfectamente á la humedad, plantillas ó zuelas para el calzado, tubos de todos calibres para conducir líquidos, impermeables pira los vestidos, bastones, látigos, cilindros para impresión tipográfica, instrumentos de cirujía, sondas, vasos de toda especie, moldes, cables telegráficos y centenares de objetos de utilidad ó de ornato, así como también para hacer las telas impermeables. Entre nosotros se usa esta substancia como goma de mascar, para hacer flores que se tiñen de diversas maneras, muñecos y pequeñas vejigas imitando á las burbujas de jabón.

Se confeccionan también con la misma substancia tubos acústicos y tubos que sirven para sostener los hilos eléctricos de los telégrafos submarinos, porque la $G u$ tapercha tiene la notable propiedad, cuando está pura, de ser poco conductora de la electricidad, como la resina y el vidrio.

Últimamente se ha tenido la idea de someter la Gutapercha á la vulcanización, sola ó mezclada con dos veces su peso de caucho, para darle mayor solidez y más resistencia á temperaturas elevadas: de esta manera se ha hecho más propia para la confección del calzado, rodajas de llaves, obturadores y válvulas para los aparatos de aguas gaseosas, etc., etc.

La solución de Gutapercha en el sulfuro de carbono, descolorada con carbón animal á un suave calor, deja depositar por la evaporación, sobre la superficie de un vidrio, láminas muy delgadas, homogéneas, de una blancura semejante al marfil, y que presentan el aspecto y semitransparencia del papel. M. Perrot ha podido servirse de ellas para sacar pruebas de grabado y litografía. Calentando estas hojas arriba de $60^{\circ}$, su porosidad disminuye y toma el aspecto de papel aceitado.

En los Estados Unidos nuestro chicle ha sido empleado para venderlo en pastillas ó pequeños cilindros, á los que se les mezcla substancias béquicas como el orozús, ó tónicos digestivos como la menta, y son vendidas como pastillas medicinales.

Para dar una idea de la importancia industrial de nuestro chicle, el Sr.J.N. Rose (1) ha publicado una tabla comparativa de las cantidades anuales que fueron recibidas en Nueva York en los años de 97 y 98 y que llegan á la suma de 1 á 2.600,000 libras, variando su precio de 23 á $27 / 2$ centavos oro la libra. Dice, y con razón, que la planta que se explota más en nuestro suelo para la extracción del chicle es el Chico zapote.

(1) Contr. U. S. Nat. Herb., p. 222. 
He recogido algunos datos recientemente de un periódico de la capital («El Mundo», 17 de Diciembre de 1901) y son los siguientes:

«Se recibieron noticias acerca de la exportación del chicle mexicano á los mer* cados del país vecino. Solamente en el trancurso de una quincena y en el solo merca« do de Nueva York, se realizaron cientu cuarenta mil libras de este artículo, habién"dose embarcado la mayor parte en los puertos de Tampico y Progreso.»

"La demanda de la mercancía sigue firme y hay tendencias de alza en los precios * de la mercancía mexicana, pues de veintinueve centavos oro á que vale la libra, lle"gará á venderse á treinta y uno.»

El Sr. Rose asegura también que la Vitellaria mammosa, (L.) RADLK., así como otras especies del género Vitellaria, producen chicle; pero que la mejor goma usada como masticatorio es la Vitellaria mammosa.

Se ve por esta corta reseña la grande importancia que tiene para la industria nuestro chicle, que además de los usos arriba dichos, tiene hoy mucha demanda para los cables de tracción eléctrica, hilos telegráficos y telefónicos, llantas de automóviles y bicicletas. Sea como substancia aisladora, $\delta$ vulcanizándola, puede reemplazar al caucho en las numerosas aplicaciones de este producto.

No cabe duda que nuestro suelo es sumamente rico en la producción de estas plantas, que como el mamey, el chico zapote, los tempixques, las bumelias, etc. etc., y todos los zapotes en general, abundan en diversas regiones de la República, sobre todo en los estados de Veracruz, Oaxaca, Guerrero, Morelos, Michoacán, Tamaulipas, Colima, etc., etc., donde existen numerosas poblaciones que conservan aún los nombres de Zapotlán, Zapotitlán, Zapotlanejo, etc., que indican la existencia de los zapotes desde los tiempos más remotos.

Pongo á continuación los zapotes de Hernández que han podido ser identificados, y que todos corresponden en lo general á la familia de las Zapotáceas y sus afines, sin mencionar las demás especies conocidas hasta hoy, por no ser mi objeto la enumeración de todas, sino exclusivamente la identificación de las plantas mencionadas por Hernández, anotándolas con los nombres mexicanos, vulgares y su lugar de habitación; mencionando, por último, los falsos zapotes, que llamo así por no pertenecer á la familia de las Zapotáceas.

ANONÁCEAS.

Anona cherimolia, Mill. Dict. ed. 9, n. 5; Bot. Mag. t. 2011. Anona tripetala, AIr.

N. Mex. Quauhtzapotl, Matzapotl, Texaltzapotl. N. V. Chirimoya, Anona.

Cultivada en Orizaba, Jalapa (Est. De Veracruz). Cuernavaca (Est. DE Morelos). Huayacocotla (Est. DE PUERLA).

Anona muricata, Lins. Sp. Pl. p. 756; JAcQ. Obs. I, t. 5. Anona bonplandiana, H. B. K.

N. Mex. Illamatsapotl. N. Maya. Polvox. N. 'V. Anona, Guanabano, en las Antillas; Hama, Zapote de viejas, Cabeza de negro.

Cultivada en varios lugares de la República.

Anona squamosa, Lins. Sp. Pl. p. 757; JAcQ. Obs. I, t. 6, fig. 1.

N. Mex. Quauhtzapotl, Ahate. N. Maya. Jalmuy ó Saramuyo. N. V. Anona, Chirimoya, Ales. 
Hay otras varias especies de anonas, que la mayor parte son cultivadas, como la Anona excelsa, A. globiflora, A. involucrata, etc., que llegan á 10012 especies más.

\section{TERnSTREMIACEAS.}

Dupinia tepezapote, Durand, Ind. p. 33.

Terustrœuia tepezapote, $\mathrm{CH}_{\mathrm{H}}$. Schl. in Linnæa, vı, p. 420; WalP. Rep. I, p. 369.

Terustromia sylvatica, CH. Schl. in Linnæa, v, p. 220.

Terustræmia lineata, DC. Prodr. I, p. 523.

Ternstrœunia meridionalis, Moc. et Sessé, Pl. Nov. Hisp. p. 80.

Terustrcunia altamirania, Schiede, ex Farmacopea mexicana.

N. Mex. Tepetzapotl. N. V. Tepezapote, Hicrba del cura.

Hab. Mazatlán, Tecolutla, Chiconquaque, Jalapa, San Andrés, San Miguel del Soldado y Valle de México.

\section{RutícEAS}

Casimiroa edulis, Llave et Lex. Nov. Veg. Descr. I1, p. 2; Seem. Bot. Voy. «Herald,» p. 273,

t. 51 et 52 .

Zanthoxylou araliacerm, Turcz.

N. Mex. Cochiztzapotl, Iztactzapotl. N. V. Zapote blanco.

Sinaloa y Durango, Zimapán y Orizaba.

Casimiroa pubescens, J. Raı. Anal. Inst. Méd. Nac. It, p. 18; La Natur., II, p. 492.

N. V. Zapote de rata.

Sierra Gorda (Est. DE Querétaro).

\section{ZaPOTÁCEAS.}

Vitellaria campechiana, (H. B. K.) RADLK.

Lucuma campechiana, H. B. K. Nov. Gen. et Sp. III, p. 240; DC. Prodr. vil, p. 171.

Según DC. esta especie es dudosa y podría ser un Sideroxylon.

Campeche.

Vitellaria domingensis, (DC.) RADLK.

Lucuma domingensis, GerTn. f, Carp. III, p. 131, t. 204.

N. V. Zapote de Sto. Domingo ó de Haiti, Mamey.

Cultivada en Cuernavaca (Est. DE MoReLos).

Vitellaria mammosa, (L.) RADLK.

Lucuma mammosa, GÆrTn. fil. Fruct. In, p. 129, tt. 203, 204; J.tcQ. Amer. t. 182, fig. 19;

DC. Prodr. vill, p. 169.

Achras manmuosa, Moc. et Sessé. Pl. Nov. Hisp. p. 48.

N. Mex. Tezontzapotl. N. V. Mantey.

Cuernavaca (Est. DE MoRei.os), Oaxaca, Veracruz, Guerrero; y en lugares cálidos. 
Vitellaria salicifolia, (H. B. K.) RADLK.

Lucuma salicifolia, H. B. K. Nov. Gen. et Sp. In, p. 241; DC. Prodr. vin, p. 171.

Achras salicifolia, Moc. et Sesse, Pl. Nov. Hisp. p. 49.

N. Mex. Atzapotl, Coztictzapotl. N. V. Zapote amarillo, Zapote borracho.

Cuernavaca (EsT. DE MoRelos) y en lugares cálidos de la República.

Vitellaria sphærocarpa, (DC.) RADLK.

Lucuma sphcerocarpa, A. DC. Prodr. vili, p. 169.

N. Mex. Tempixque ó Tempixtle. N. V. Mamey. Según Oliva, Comingalo.

México.

Achras sapota, Linv. Sp. Pl. p. 470; Bot. Mag. tt. 3111, 3112; Moc. et Sessé, PI. Nov. Hisp. p. 48.

Sapota achras, MiLl. Bot. Mag. tt. 3111, 3112; Biol. Centr. Am. Bot. II, p. 297.

N. Mex. Chictzapotl, Xicotzapotl. N. V. Chicozapote, Zapote de abejas, Peruétano.

Yucatán, Colima, Tamaulipas.

Sideroxylon leucophyllum, Wats. Proc. Am. Acad. xxiv, p. 59.

Bahía de los Ángeles (Baja California).

Sideroxylon mexicanum, Hemsl. Biol. Centr. Am. Bot. II, p. 296.

Achras capiri, Moc. et Sessé, Pl. Nov. Hisp. p. 48 et Fl. Mex. p. 84.

Lucuma? capiri, A. DC. Prodr. viI, p. 173.

N. Mex. Tototzapotl. N. V. Capiri. Zapote de ave.

Ario, Taretan (Est. DE MichoAcÁn), Cutzamala y Tlachapa (Est. DE Guerrero).

Sideroxylon petiolare, A. Gray. Proc. Am. Acad. xxir, p. 434.

La Barranca (Est. DE JALIsCo).

Nota.-Da un fruto comestible, que es una baya de más de una pulgada, semilla ovalada y albuminosa, muy parecida al Lucuma? ferruginea.

Bumelia læte-virens, Hemsl. Biol. Centr. Am. Bot. 11, p. 298.

Achras olivacea, Moc. et Sessé. Fl. Mex. p. 84.

N. Mex. Tempizquixtli. N. V. Tempixtle.

Oaxaca y Orizaba.

Nota.-El dibujo mexicano á que alude Decandolle puede representar, según Hemsley, á la Bumelia late-virens y no á la B. lycioides, por tener un parecido completo en la forma de las hojas.

Bumelia subsessiliflora, Hemsl. Biol. Centr. Am. Bot. II, p. 299.

N. Mex. Tempizquixtli. N. V. Tempixtle. Tilapos.

Guadalajara.

Además, se encuentran otras siete especies de Bumelias en distintos lugares de la República.

Diospyros ebenaster, Retz. Obs. Bot. Fasc. v, p. 31; Hiern. in Trans. Camb. Phil. Soc. xil, p. 244.

Diospyros obtusifolia, H. B. K. Nov. Gen. et Sp. III, p. 253, t. 247.

Diospyros tliltzapotl, Moc. et Sessé. Fl. Mex. ed. fom. p. 237.

N. Mex. Tliltzapotl, Totocuitlatzapotl. N. V. Zapote negro, Zapote prieto.

México, Cuernavaca.

Nora.-Además de éstas se encuentran cuatro especies más en la República. 


\section{FALSOS ZAPOTES.}

\section{CAPARIDEAS.}

Cratæva sp. Rose, Contr. U. S. Nat, Herb. I, p. 301.

N. V. Zapotillo amarillo.

Manzanillo (Est. DE Colima).

\section{MaLPigiaceas.}

Bunchosia biocellata, ScHL. in Linnæa, x, p. 241.

Bunchosia discolor? Turcz. in Bull. Soc. Nat. Uvic. 1858, I, p. 266.

Bunchosia lanceolata? Turcz. loc. cit.

N. V. Zapotito de S. Juan.

Orizaba, Córdoba, Jalapa (Est. DE VERACRUz).

ROSÁCEAS.

Couepia polyandra, Rose, Contr. U. S. Nat. Herb. v, pp. 196-216.

Hirtella polyandra, H. B. K. Nov. Gen. et Sp. p. 246, t. 565.

Moquilea kunthiana, MaRT. et Zucc., ex Walp. Rep. II, p. 6.

Couepia kunthiana, Benth. M. S. in hb. Kew.

N. V. Zapote amarillo.

Acapulco (Est. DE Guerrero). Teapa (Est. DE Tabasco). Acaponeta (TePIC).

Muy común en las costas de México.

\section{FitolacácEas.}

Phytolacca dioica, Lins. Sp. P1. p. 532.

Pircunia dioica, DC. Prodr. 2 part. p. 30.

N. V. Tepezapote, según Oliva.

Esta planta no es mexicana, pero ha sido aclimatada ya. Creo que el Sr. Oliva la confundió con la Ph. octandra que se encuentra en Orizaba, Córdoba y Valle de México, y en varios lugares de la República. 





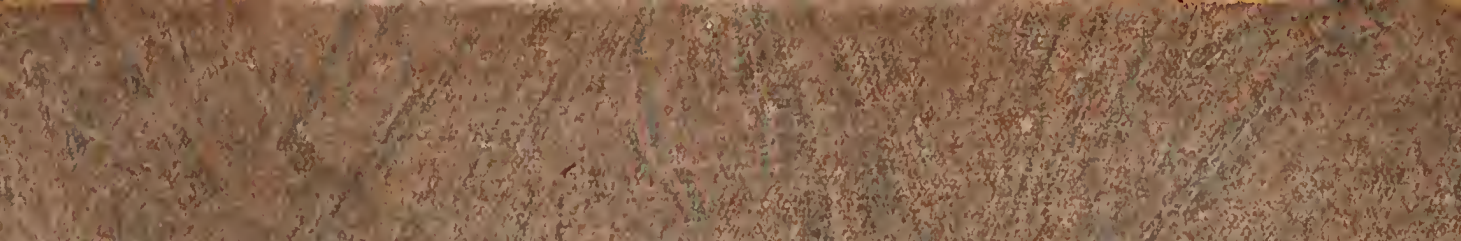

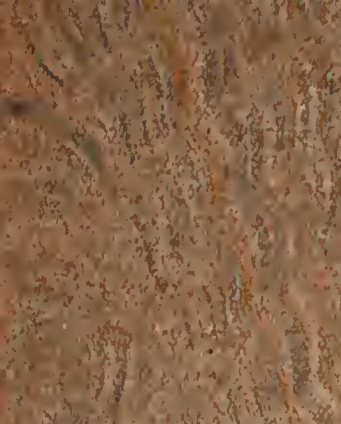

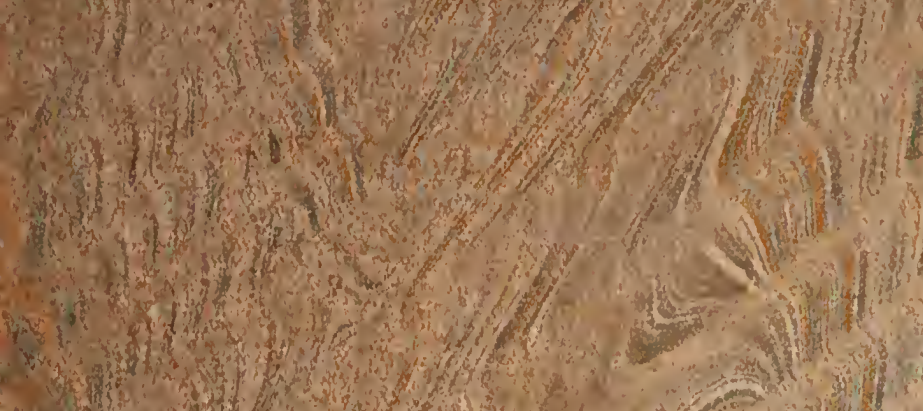

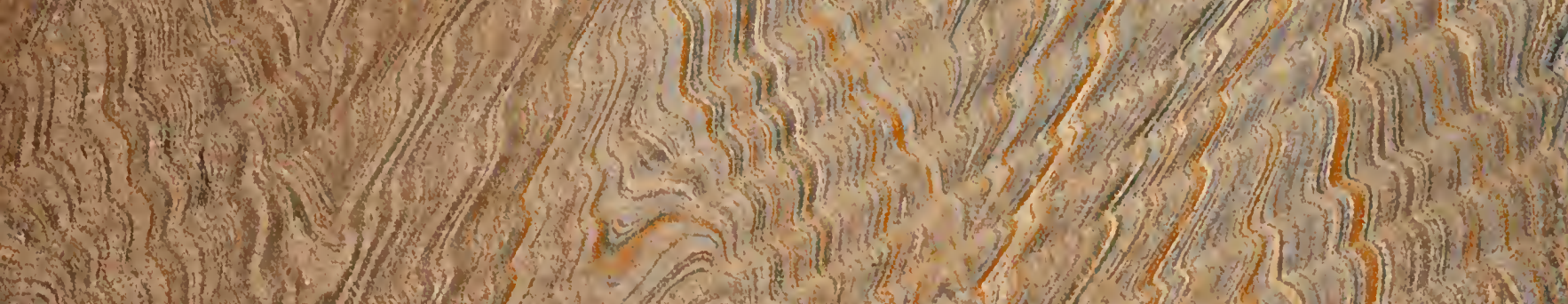
-

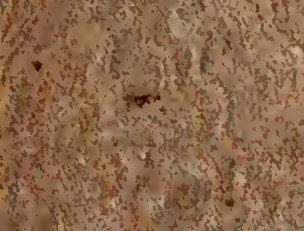

